\title{
CHARACTERIZATION OF MULTI-BARGE FLOTILLA IMPACT FORCES ON WALL STRUCTURES
}

\section{By: Robert A. Walters a, Michael T. Davidson b, Gary R. Consolazio c, Robert C. Patev d}

a University of Florida, Department of Civil and Coastal Engineering, P.O. 116580, Gainesville, FL 32611, USA (E-mail: RWALTERS@WALTERPMOORE.COM)

b University of Florida, Bridge Software Institute, P.O. 116580, Gainesville, FL 32611, USA (E-mail: MICHAEL@CE.UFL.EDU)

${ }^{\mathrm{c}}$ Corresponding author: University of Florida, Department of Civil and Coastal Engineering, P.O. 116580, Gainesville, FL 32611, USA (Tel: +1 352294 7796. Fax: +1 352392 3394. E-mail: GRC@CE.UFL.EDU)

d United States Army Corps of Engineers, Risk Management Center, 696 Virginia Road, Concord, Massachusetts 01742, USA (E-mail: ROBERT.C.PATEV@USACE.ARMY . MIL)

\section{Abstract}

Engineering standards employed in the United States to design concrete waterway control structures for barge impact loading are principally based on data collected from full-scale experimental barge flotilla (barge tow) impact tests. Due to logistical constraints and test costs, the range of parameters that can be varied during physical experiments is typically limited. Consequently, design standards based on such tests have the potential to be undesirably conservative with respect to determination of design impact loads. In the present study, analytical techniques (numerical simulations) are used to quantify barge impact loads over a wider range of conditions than that which would typically be feasible using experimental testing. Nonlinear dynamic finite element models of barge flotillas are developed to accurately represent inelastic barge crushing and inter-barge wire-rope lashing behavior. The models are validated against experimental test data and subsequently used to conduct parametric studies to quantify the influences of impact speed, impact angle, flotilla size, and load measurement technique. A key finding - with implications for design efficiency - is that flotilla impact loads are strongly 
correlated to the momentum of only barges in the lead row of a flotilla, rather than total momentum of the entire flotilla, as has been assumed in the development of past design standards. Furthermore, it is found that the load measurement technique used in prior experimental impact tests artificially increased the measured loads, relative to impacts from non-instrumented barges, thereby introducing additional conservatism into previously developed design standards.

\section{Keywords}

Barge impact load; Wall design; Finite element analysis; Experimental testing; Momentum

\section{Highlights}

- $\quad$ Design loads for multi-barge flotilla impacts against wall structures are quantified using finite element impact simulations

- $\quad$ Full-scale experimental test data are used to validate the finite element models

- Simulation results suggest that devices employed in experimental impact testing can artificially increase measured forces thereby leading to conservatism in design

- Peak impact forces correlate more strongly with the momentum of the lead row of barges in a flotilla than with the momentum of the entire flotilla

\section{Introduction}

Most navigable waterways in the United States (U.S.) have the capacity to support mass transit of materials through the use of barges. During transit, barges often navigate within close proximity to waterway structures, thus posing potential collision risks. Navigational wall structures serve an important role in helping to ensure safe commodity-transport operations near locks and dams. Approach walls, for example, allow barge pilots to execute controlled alignment maneuvers prior to entering locks, but also protect nearby waterway facilities (e.g., hydroelectric 
dams, gates) from potential damage by either errant or loose barges. Considering that nearly 200 lock sites are distributed along U.S. navigable waterways, wall structures are subjected to nearly daily impacts from vessels, including multi-barge flotillas. As defined here, a barge 'flotilla' is a collection of individual barges, typically arranged end-to-end in one or more columns (Fig. 1). Inter-barge lashings, commonly consisting of steel wire rope cables, secure the individual barges together into an integral unit that can be efficiently propelled along navigable waterways using a single (trailing) push boat.

Loads that are associated with accidental barge impacts often control the design of guidance structures and protection systems on navigable waterways. Design procedures [1] currently employed by the U.S. Army Corps of Engineers (USACE) to calculate barge impact loads on navigation wall structures are based primarily on data collected from (physical) experimental tests [2] of barge impacts on rigid concrete wall structures. However, the inventory of navigational structures designed and maintained by the USACE also includes walls of varying levels of structural flexibility.

It is therefore the objective of the present study to determine whether current procedures for calculating design impact loads yield structural designs with suitable conservatism, or excess conservatism, when applied to either rigid wall systems or flexible wall systems. To achieve this objective, finite element (FE) modeling and impact simulation techniques are employed to quantify barge collision loads on wall structures — of varying stiffnesses — over a range of different impact conditions (speed, angle, flotilla size). Integration of such data into the development of future design procedures will lead to navigational wall structures that satisfy more precise definitions of impact resistance while remaining economical. 


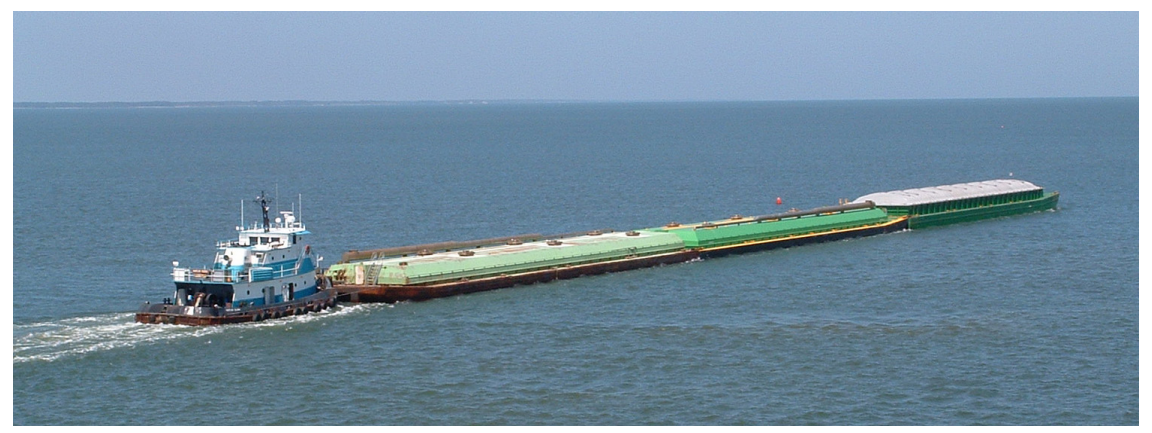

Figure 1. One-column, three-row (1x3) flotilla moving along the Intracoastal Waterway in Florida

\section{Background}

Several prior research efforts aimed at quantifying loads associated with vessel impacts on waterway structures have addressed highway bridge structures. Bridge design codes in the U.S. [3] and Europe [4] prescribe methods for estimating ship impact loads and barge impact loads, and stipulate related structural design requirements. Numerical modeling and analytical techniques have been developed to facilitate design-level loading and response characterizations for ship collisions with bridges $([5,6])$. Several studies have also been carried out to refine U.S. code provisions by developing barge impact load prediction procedures with improved accuracy $([7,8])$ and improved analysis procedures $([9,10,11])$. However, such advances are specific to bridge structures, where a significant portion of structural mass is typically located well above the waterline - and thus well above the practical range of barge impact elevations. Consequently, dynamic responses exhibited by bridge structures differ fundamentally from those of wall structures when subjected to impact loads. Furthermore, procedures developed as part of the aforementioned studies involved examination of nearly-head-on impact conditions, in which the vessel is brought to an abrupt halt. In contrast, barge flotilla collisions with wall structures generally involve shallow angle 'glancing' (i.e., re-directional) impacts, in which the barge slides along the wall rather than being halted. Consequently, because the collision mechanics of barge-bridge impacts differ from those of barge-wall impacts, empirical relationships between 
energy, momentum, and force developed for barge-bridge interactions do not necessarily apply to barge-wall interactions.

To address this discrepancy, the USACE previously conducted experimental research focusing specifically on barge impact forces on waterway structures such as lock approach walls. Several series of full-scale barge flotilla impact experiments were conducted to quantify impact forces on rigid concrete walls $[2,12]$, as well as semi-flexible prestressed concrete guide walls [13]. Additionally, the USACE has carried out related analytical studies [14] to investigate barge deformation mechanics during wall impacts. These prior research efforts (in particular $[2,12]$ ) culminated in the development of the design provisions and load prediction equations contained in USACE ETL 1110-02-563 [1].

Due to the complexities associated with conducting full-scale flotilla impacts in a controlled manner, only barge impact speeds and approach angles were varied during the USACE experiments that formed the basis of ETL 1110-02-563. Consequently, it was not feasible to experimentally explore, or quantify, the important effects that flotilla size (e.g., number of barge rows in the flotilla) has on impact forces. Additionally, experimental instrumentation used by the USACE to measure impact forces during the experiments - a steel load-measurement beam affixed to the bow corner of the impacting barge-was suspected to have increased the effective stiffness of the barge impact zone, and thus, also increased the measured forces. Moreover, for reasons of both safety and economy, the USACE experiments were conducted at relatively low speeds (and low energies). Therefore, it was not possible to characterize-in a controlled experimental manner-the extent to which inelastic barge crushing, energy dissipation, and lashing failure influence the generation of impact forces during high-energy collision scenarios. 


\section{Finite Element Modeling of Multi-Barge Flotillas and Wall Structures}

In the present study, FE modeling and analysis techniques are used to address knowledge gaps that have arisen from developing barge impact design recommendations based solely on full-scale physical experimentation. Accordingly, impact forces are quantified over a wide range of collision scenarios, including variations of wall stiffness, impact speed, impact angle, barge damage severity, and (most importantly) flotilla size. The FE models are additionally validated against available USACE rigid wall and semi-flexible wall test data. Subsequently, simulations are carried out over a range of barge-wall impact conditions, which would be prohibitively costly and potentially unsafe to study experimentally. In this way, a parametric force dataset is generated in a manner that, otherwise, would be impractical to achieve. In the sections that follow, descriptions are given for the FE models used to carry out this process.

\subsection{Barge Flotilla}

The FE models of barge flotillas (Fig. 2) developed and employed in this study make use of the LS-DYNA FE code [15] for purposes of conducting nonlinear dynamic barge-wall collision simulations. Each flotilla model is comprised of multiple, individual jumbo hopper barges $59.5 \mathrm{~m}$

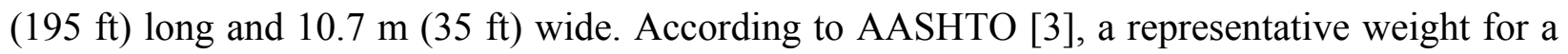
jumbo hopper barge fully-loaded with cargo is $16.9 \mathrm{MN}$ (1900 tons). Combining this value with an approximate hydrodynamic mass coefficient of $C_{H}=1.05$ [3] yields an effective impact weight of 17.7 MN (1995 tons). This value is rounded to $17.8 \mathrm{MN}$ (2000 tons) and assigned to each barge in the flotilla model.

Two flotilla sizes are considered (Fig. 3): a $3 \times 3$ flotilla (3 columns wide, 3 rows long), and a $3 \times 5$ flotilla ( 3 columns wide, 5 rows long). Within each flotilla, two 'jumbo hopper barge' configurations are present: 1) single-raked barges, which are raked (tapered in depth) only at the 
bow; and, 2) double-raked barges, which are raked at both the bow and stern. Single-raked barges are positioned at the lead and trailing rows of each flotilla, while double-raked barges make up the interior rows (Fig. 3).

Characteristics of the $3 \times 3$ flotilla are: $178.3 \mathrm{~m}$ (585 ft) long, $32.0 \mathrm{~m}(105 \mathrm{ft})$ wide, with a total effective weight (i.e., vessel + payload + hydrodynamic) of $160.1 \mathrm{MN}(18,000$ tons). The $3 \times 5$

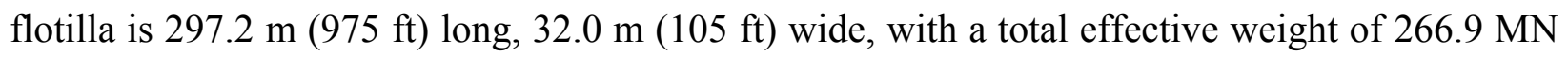
(30,000 tons). A sizable portion of the overall flotilla weight is attributable to the weight of transported material (i.e., payload), which is distributed throughout the hopper region of each barge. Payload weight is calibrated (as discussed in greater detail in [16]) such that the effective weight of each unloaded 'bare' steel barge plus the weight of the payload sums to a total of 17.8 $\mathrm{MN}(2,000$ tons).

Together with application of a vertical gravity field, vertical buoyancy forces are incorporated into the flotilla FE models: each barge is suspended by vertical, tension-only discrete springs, which attach to all bottom-surface nodes. To ensure that nodal buoyancy forces are generated only during times in which the nodes are submerged, gaps are incorporated into the buoyancy spring force-deformation definitions (see [17] for details regarding gap spring calibration and initialization). Including both gravity (body forces) and buoyancy effects permits the barges to emulate pitching and rolling motions that may occur during impact. 


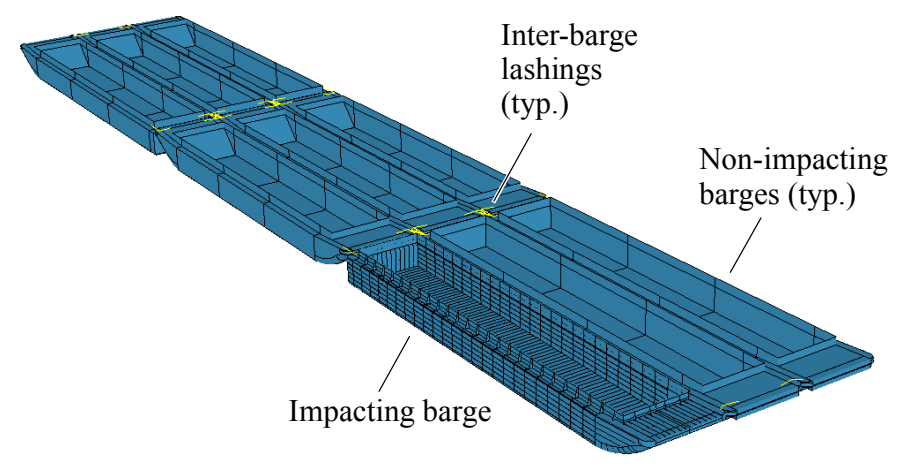

Figure 2. Finite element model of a $3 \times 3$ flotilla (mesh not shown for clarity)

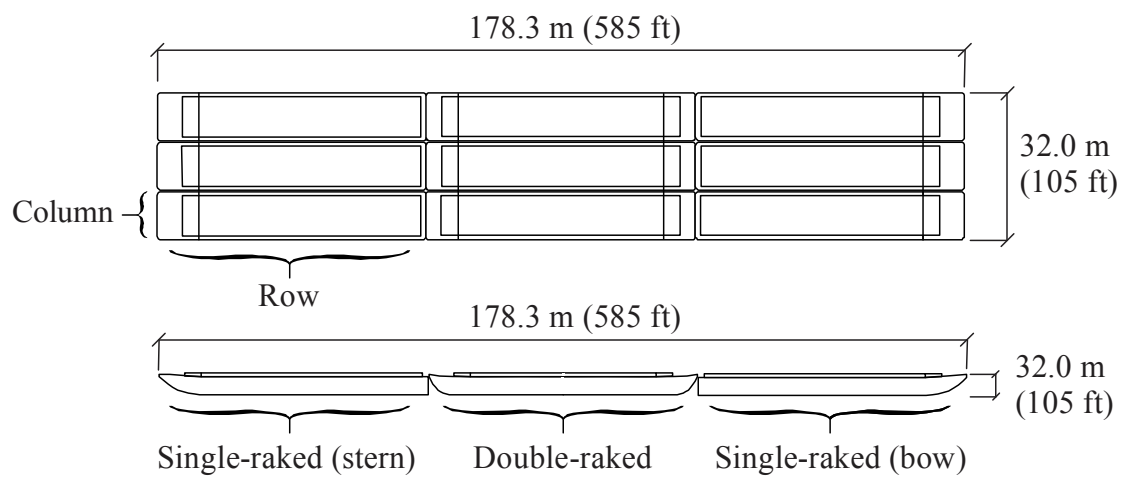

a)
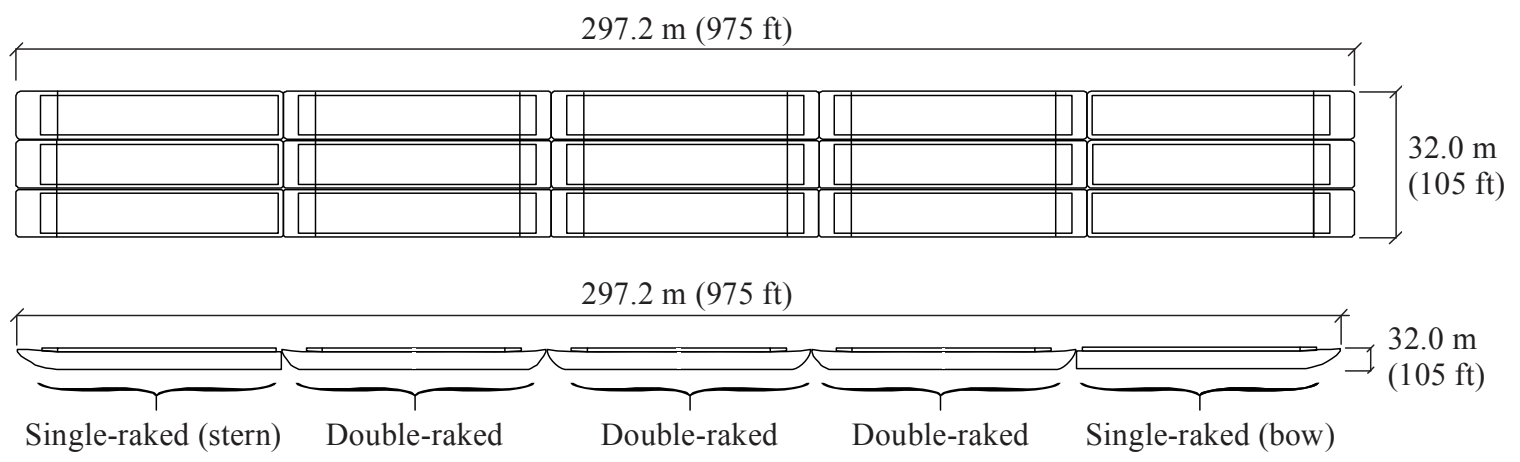

b)

Figure 3. Jumbo hopper barge flotilla schematics:

a) $3 \times 3$ plan and elevation; b) $3 \times 5$ plan and elevation

\subsubsection{Impacting Barge}

A single-raked jumbo hopper barge (Fig. 5a) is designated as the 'impacting barge' (i.e., the barge that makes initial contact with the wall) in each flotilla model considered herein. Longitudinally, the impacting barge is divided into three zones: $8.38 \mathrm{~m}(27.5 \mathrm{ft})$ for the bow 
(Fig. 5b); $49.4 \mathrm{~m} \mathrm{(162} \mathrm{ft)} \mathrm{for} \mathrm{the} \mathrm{hopper} \mathrm{(Fig.} \mathrm{5c);} \mathrm{and} 1.68 \mathrm{~m} \mathrm{(5.5} \mathrm{ft)} \mathrm{for} \mathrm{the} \mathrm{stern} \mathrm{(Fig.} \mathrm{5d).}$ Watertight bulkheads are used to compartmentalize the hopper zone, and are spaced at $12.3 \mathrm{~m}$ $(40.5 \mathrm{ft})$ intervals.

The impacting barge model consists of a mesh of more than 900,000 fully-integrated nonlinear shell elements (typically $76 \mathrm{~mm}$ by $76 \mathrm{~mm}, 3$ in by $3 \mathrm{in}$, in size), and is consistent with detailed structural plans obtained from a major barge manufacturer. Each of the three barge zones consists of internal structural members (primarily channels, angles, and gusset plates) and external hull plates, with element thicknesses varying between $7.9 \mathrm{~mm}(5 / 16 \mathrm{in})$ and $15.9 \mathrm{~mm}(5 / 8 \mathrm{in})$. Barges fabricated in the U.S. are commonly constructed using ASTM A36 structural steel, and so, a strain-rate dependent nonlinear constitutive relationship (effective-true-stress vs. effective-plastic-strain) for A36 structural steel (Fig. 4 [16]) is employed for all shell elements in the impacting barge model. Strain-rate effects are modeled using the Cowper-Symonds model:

$$
\frac{\sigma_{\text {dynamic }}^{y}}{\sigma_{\text {static }}^{y}}=\left[1+\left(\frac{\dot{\varepsilon}_{\text {eff }}^{p}}{C}\right)^{\frac{1}{P}}\right]
$$

where dynamic yield stress $\left(\sigma_{\text {dynamic }}^{y}\right)$ is obtained by modifying the static yield stress $\left(\sigma_{\text {static }}^{y}\right)$ based on the effective plastic strain rate $\left(\dot{\varepsilon}_{e f f}^{p}\right)$ and two material-dependent parameters, $C$ and $P$. For mild steel, $\mathrm{C}$ and $\mathrm{P}$ are taken as $40.5 \mathrm{sec}^{-1}$ and 5, respectively, per [18]. 


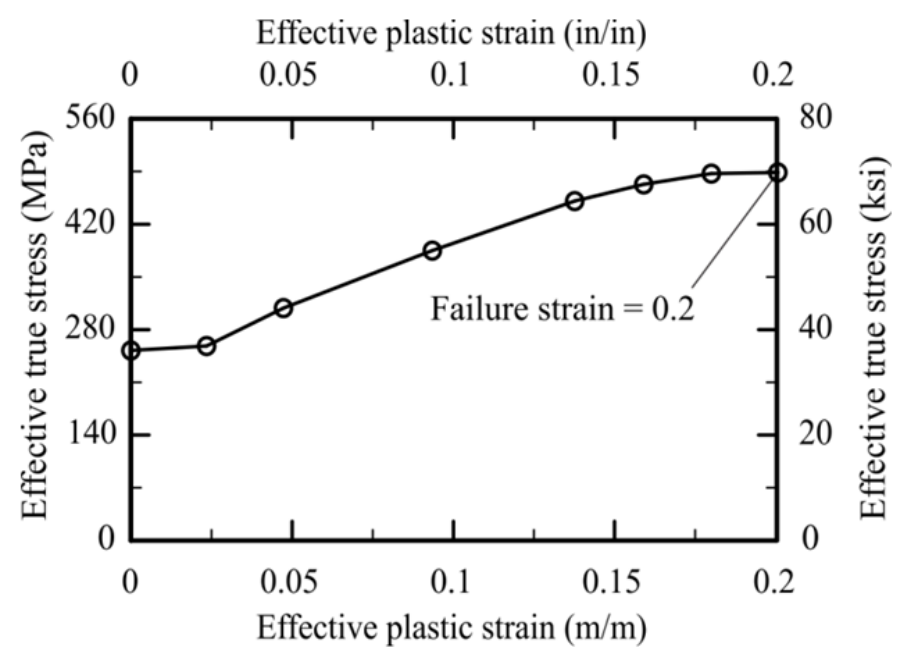

Figure 4. Barge structural steel material parameters [16]

In physical barge construction, individual (non-contiguous) steel components are joined together via welds. In the FE model, spotwelds are modeled using rigid massless beams (*CONSTRAINED_SPOTWELD in LS-DYNA [15]), which transmit moment, shear, and normal force between nodes from elements of adjacent structural members. Weld failure is approximated in the model through element deletion upon failure of one of two adjoined shell elements (the base material is assumed to reach failure strain, $0.2 \mathrm{~mm} / \mathrm{mm}$, prior to spotweld failure). Spotwelds within the barge model are distributed at a sufficient density so as to reasonably emulate the weld patterns present throughout physical barges.

\subsubsection{Non-Impacting Barges}

Non-impacting barges in each flotilla FE model provide a means of representing mass-related barge inertial properties, as well as dynamic interactions between barges. Using a finely discretized (e.g., 900,000 element) barge model at each position within a multi-barge flotilla is, however, computationally inefficient and infeasible. Further, for the range of collision scenarios considered, the 'impacting barge' is the only unit in the flotilla expected to undergo concentrated, inelastic deformations. It follows that relatively limited insights would be gained (and at great computational cost) by including detailed geometric and constitutive modeling of 
internal structural members of non-impacting barges. Therefore, non-impacting barge models are similar to the impacting barge in terms of external geometry, but the internal structural configurations are wholly modified to improve numerical efficiency.

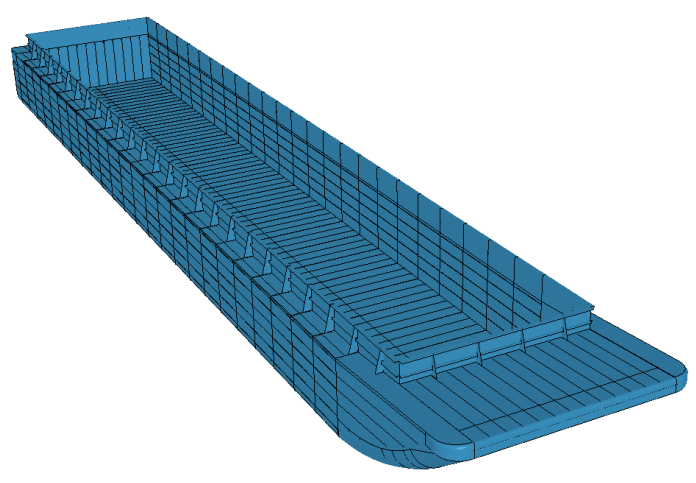

a)

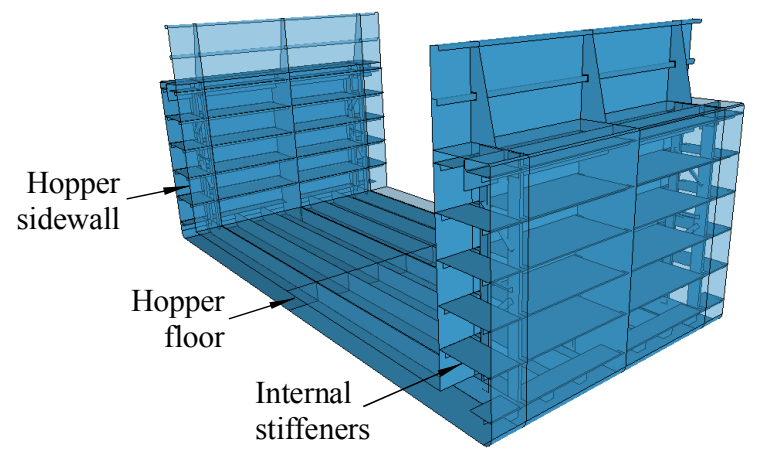

c)

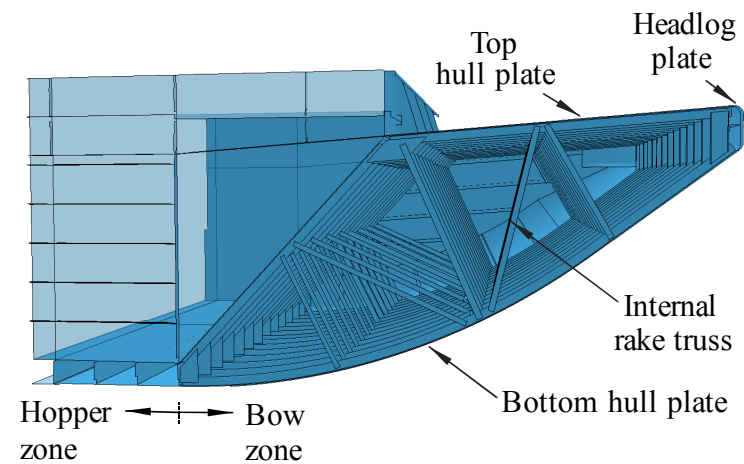

b)

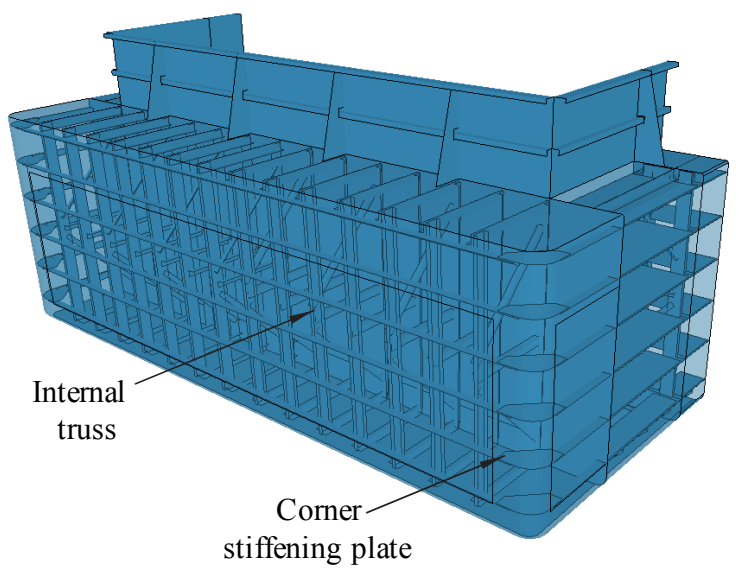

d)

Figure 5. Impacting barge model (mesh not shown for clarity):

a) Overview; b) Bow details; b) Hopper details; c) Stern details

In each non-impacting barge model, all shell elements on the exterior surfaces of the barge are 'rigidized' (i.e., made rigid), and increased in size to approximately $914 \mathrm{~mm}$ by $914 \mathrm{~mm}$ (36 in by 36 in). Deformability of the perimeter of the barge, as it relates to interactions between contacting barges, is modeled using pre-calculated user-defined non-linear force-penetration contact definitions (discussed later) rather than through detailed modeling of the barge perimeter with deformable shell elements. Therefore, given that deformability is managed through contact 
definitions rather than through deformable shell elements, internal structural shell elements (making up beams, plates, and frames) serve no purpose and are removed from the model. Although major modifications to the internal structural configuration of the non-impacting barge are made, all non-impacting barges mimic the global mass- and stiffness-related attributes of the deformable, impacting barge (e.g., mass moments of inertia, translational mass, and non-linear perimeter stiffness).

As noted previously, two variations of the non-impacting barge model are used within each flotilla model: a single-raked barge (Fig. 6a) and a double-raked barge (Fig. 6b). Note that the double-raked barge maintains the same overall dimensions as the non-impacting single-raked barge. However, the headlog of the double-raked model is more finely discretized than that of the single-raked model, which ensures robust detection of contact for both bow-to-bow and bow-to-stern interactions.

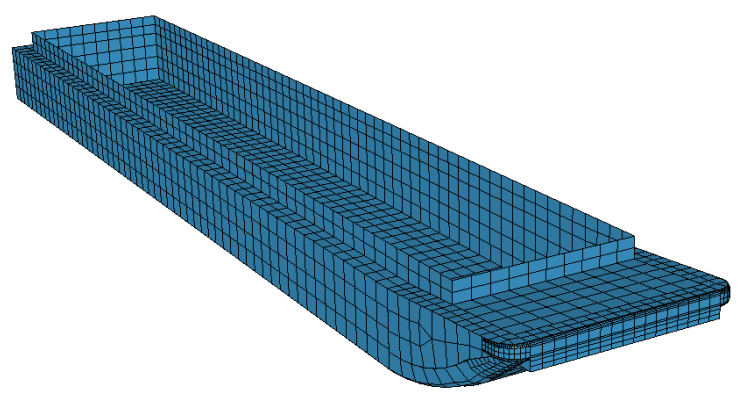

a)

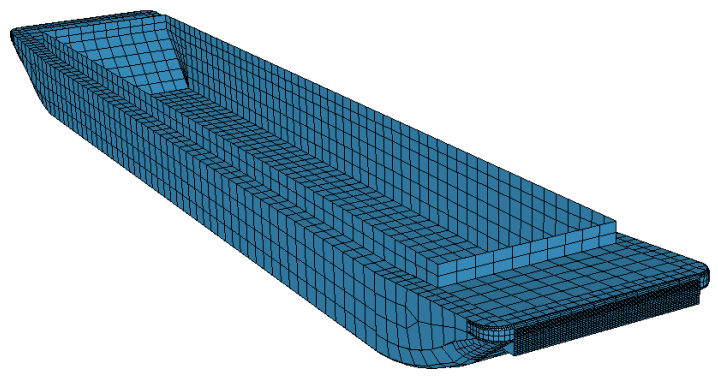

b)

Figure 6. Non-impacting, reduced resolution jumbo hopper barge FE models:

a) Single-raked model; b) Double-raked model

\subsubsection{Inter-Barge Contact}

Depending on the row and column position of a barge within the flotilla and the contact surface in question, barge-to-barge contact definitions (types) are assigned: namely, side-to-side, bow-to-bow, or bow-to-stern (Fig. 7). Barge-to-barge contact definitions in the flotilla FE model 
are included for each anticipated instance of barge-to-barge adjacency. In contrast, and to promote computational efficiency, contact types are intentionally excluded for non-adjacent barges. For example, a barge in the lead row of a flotilla is not expected to make direct contact with a barge in the trailing row, and so, no contact type is defined between these two barges.

Bow-to-stern $\leadsto$ Bow-to-bow $\leadsto$ Side-to-side ..............

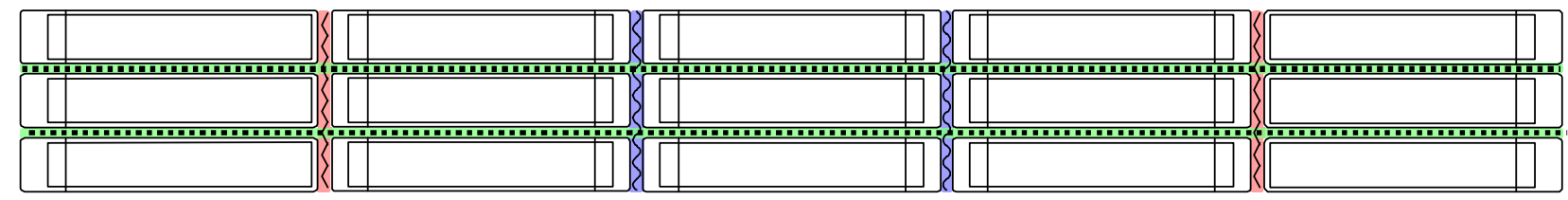

Figure 7. Barge-to-barge contact types (illustrated within in a 3x5 flotilla)

In order to represent nonlinear contact-deformations that arise between individual barge models which are perfectly (numerically) rigid, the special-purpose 'rigid body contact' algorithm *CONTACT_RIGID_BODY_ONE_WAY_TO_RIGID_BODY in LS-DYNA is utilized [15]. With this algorithm, objects that are otherwise treated as being perfectly rigid are instead permitted to penetrate each other during contact interactions, thus numerically mimicking nonlinear, large-displacement barge deformability. A user-defined nonlinear force-penetration relationship is used to quantify nodal (normal) force versus penetration through each designated rigid surface (e.g., barge perimeter). Definitions are supplied on a per-node basis, and are specific to the barge-to-barge contact type being modeled (bow-to-stern, bow-to-bow, side-to-side). As a result, when two barges come into contact, a restoring force is applied to each penetrating node. The restoring force increases as penetration increases, until sufficient force has been generated to eliminate the nodal penetration.

The force-penetration relationships supplied for each barge-to-barge contact type are derived from deformable barge crush simulations, and assigned to appropriate contact zones 
(recall Fig. 7) for each barge within the flotilla FE model. For example, bow-to-stern interactions utilize a force-penetration relationship obtained from a separate simulation of crushing between a fully deformable barge bow and fully deformable barge stern (Fig. 8a). Due to the greater stiffness of the bow, the majority of deformation was concentrated in the stern (Fig. 8b), although low-level deformation did also occur in the bow. Subsequent to carrying out the deformable bow-to-stern barge crush simulation, the total contact force parallel to the direction of crushing was paired with penetration distance, and a smoothed curve was then utilized for that type of interaction in the flotilla FE model (Fig. 8c). Corresponding simulations were carried out to additionally characterize barge-to-barge interactions for the bow-to-bow and side-to-side types [16]. Hence, although non-impacting barges are modeled using rigid shell elements, deformations arising as a result of barge-to-barge interactions are still accounted for through the use of rigid body contact definitions. 


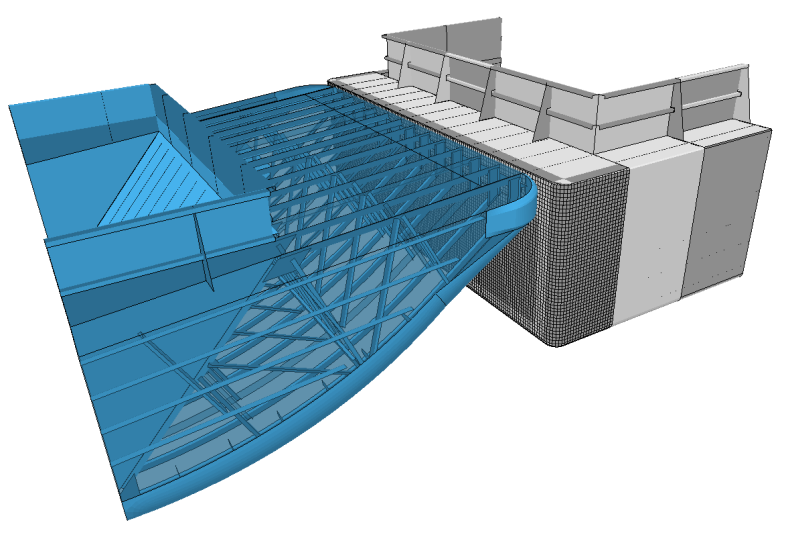

a)

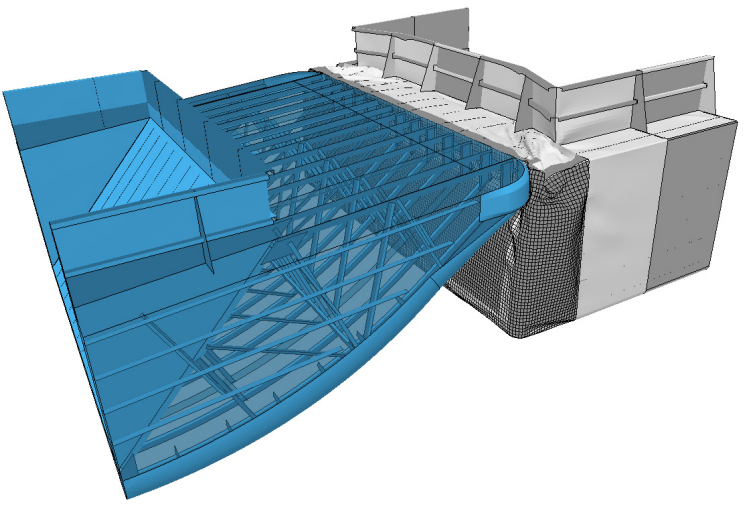

b)

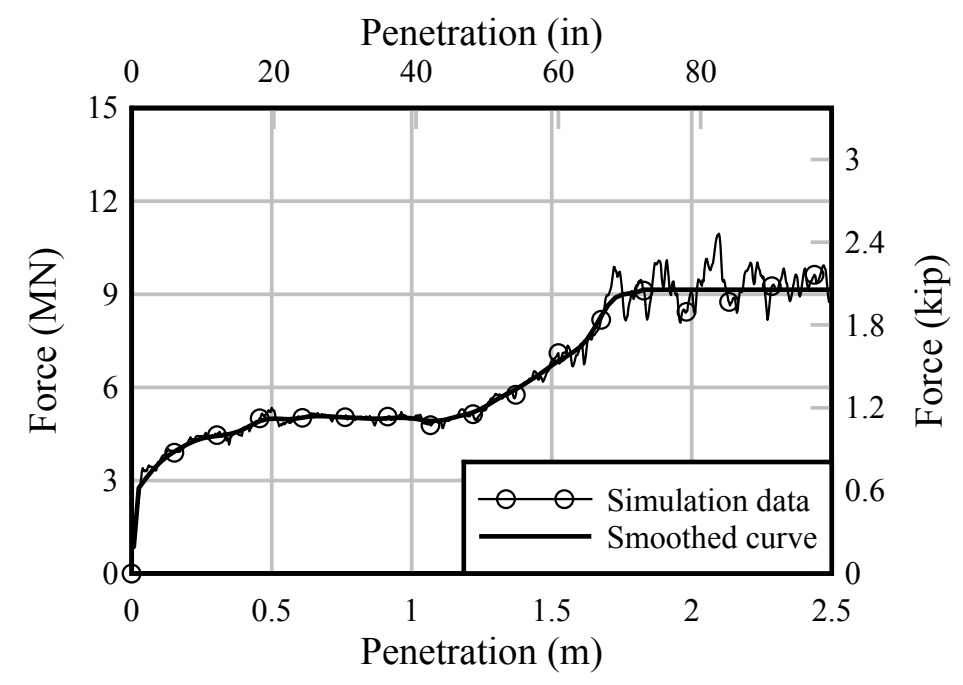

c)

Figure 8. Bow-to-stern crush simulation (for clarity, only partial mesh shown):

a) Before crush; b) During crush: c) Force-penetration relationship

\subsubsection{Lashing Cables}

Stranded wire ropes (lashings) are typically used to tie together barges within a flotilla [19]. Various configurations of lashings are used to introduce inter-barge stiffnesses, which in turn, constrain the collection of individual barges within a flotilla to behave as an integrated unit. With a lashing system in place, barges no longer act independently of one another, but rather, the relative motions of each barge propagate (via forces in the lashings) throughout the flotilla. 
Wire rope is generally composed of steel wire strands arranged in a helical pattern in one or more layers around a (fiber or steel) inner core. As given in [20], individual steel wires that make up wire rope strands are required to have a tensile failure stress between $1565 \mathrm{MPa}(227 \mathrm{ksi})$ and $1958 \mathrm{MPa}(284 \mathrm{ksi})$. In addition to variations found among the material properties of wire rope, myriad geometric configurations are encountered (in practice) for linking barges together. Tensile breaking strengths, or ultimate strengths, for several wire rope configurations are listed in [20].

Physically, a single flotilla lashing consists of a length of wire rope that is wrapped around a sequence of barge bitts and tensioned to hold two adjacent barges in place. A demonstrative, conceptual lashing configuration is shown in Fig. 9a, where commonly used configurations are given in Chapter 2 of [16]. Development of a suitable FE representation of lashings requires both constitutive and geometric considerations. Shown in Fig. $9 \mathrm{~b}$ are the FE model entities that would correspond to the physical components of Fig. 9a. Each bitt acts as a pivot point for the lashing, while still allowing the lashing to undergo slippage. Resultant forces on the bitts vary based on the tension force developed in each straight (bitt-to-bitt) segment of the lashing. If the flotilla lashing system is perturbed, slippage around the bitts is often required to maintain equilibrium. Through the combined use of LS-DYNA seatbelt elements, a failure spring, a tensioning cable, and a slack-ended retractor (Fig. 9b), the various physical behaviors of lashings (lashing pretension, slippage of lashings around barge bitts, and lashing failure) are all incorporated into the flotilla model. Chapter 4 of [16] details the lashing cable constitutive models (including pretensioning and failure), constraints, relative motions (e.g., slippage, retraction), and integration into the overall barge FE model. 


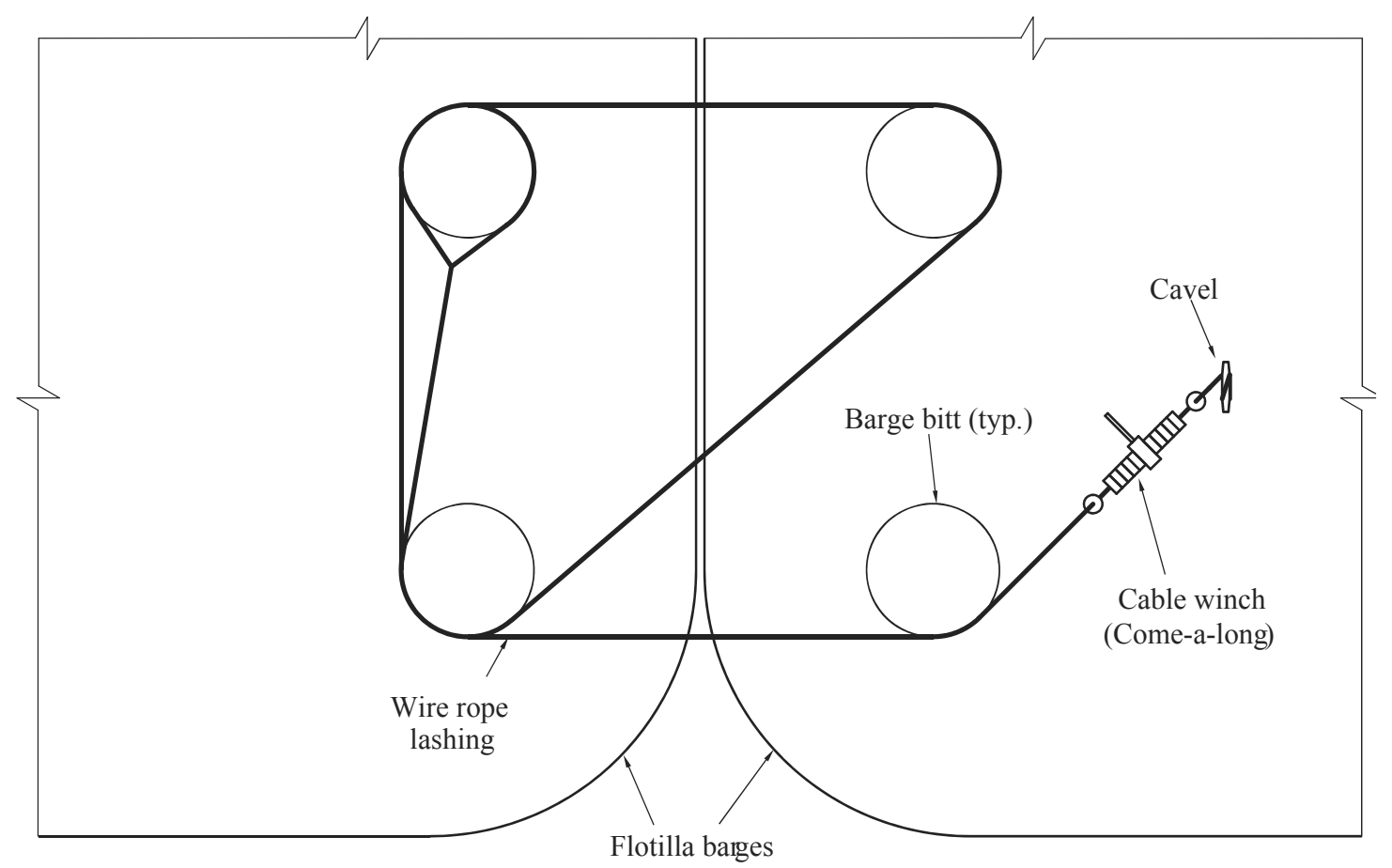

a)

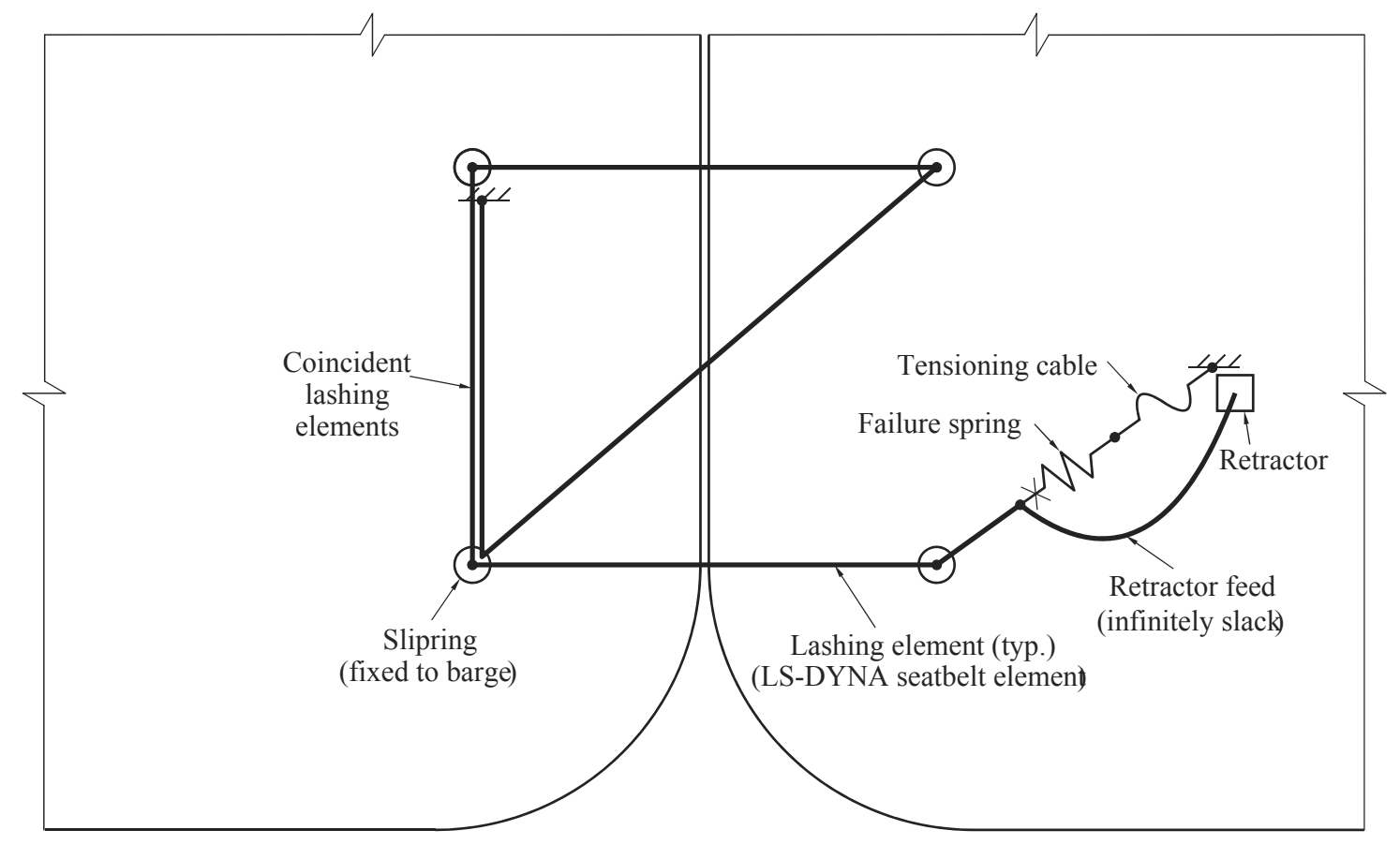

b)

Figure 9. Conceptual lashing configuration schematics: a) Physical components; b) FE model components 


\subsection{Wall Structures}

\subsubsection{Rigid Wall}

In each rigid wall simulation conducted, the flotilla is positioned (Fig. 10) to impact the wall at a specific angle of obliquity $(\theta)$ and assigned an initial velocity $\left(\mathrm{V}_{0}\right)$. With overall

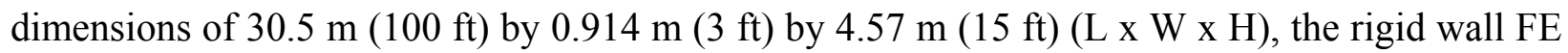
model is composed of rigid 8-node brick (solid) elements, each having a characteristic length of $0.914 \mathrm{~m}$ (36 in). All nodes in the wall FE model are fully restrained from motion, and the barge-wall contact zone is of sufficient size to ensure that the barge will not penetrate any portion of the wall located outside the extents of the defined contact surface.

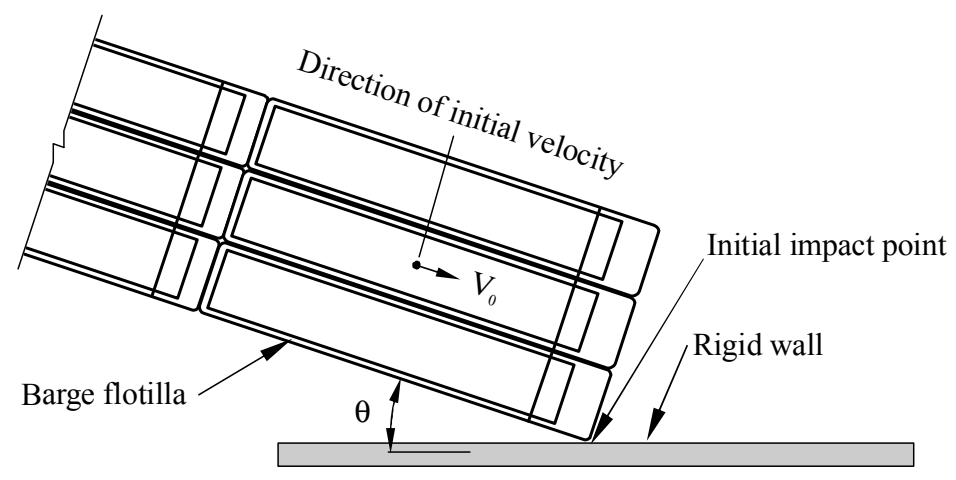

Figure 10. Schematic of flotilla impact against rigid wall

Computational efficiency is promoted by only designating contact nodes on the barge that can potentially come into contact with the wall structure during collision. Specifically, for the barge that makes primary (initial) contact with the wall, all shell elements located within the starboard half of the bow are included in the barge-wall contact definition. Contact forces that are generated possess both normal and transverse (frictional) components with respect to the rigid wall contact face. The parameters for the friction portion of the barge (steel) to rigid wall contact definition consist of 0.50 and 0.45 for static and dynamic coefficients of friction, respectively. Note that these considerations apply for both rigid wall and semi-flexible wall impact simulations. 


\subsubsection{Semi-Flexible Wall}

Spanning $36.0 \mathrm{~m}$ (118 ft) from rigid cell to rigid cell (Fig. 11), a single span of the lock approach wall at Winfield Lock and Dam $[13,21]$ in Red House, West Virginia forms the basis for the semi-flexible wall FE model. The segmental post-tensioned span is divided longitudinally into three matchcast segments of equal length, where each segment possesses a unique cross sectional shape. Solid, hollow, and transition cross sections are present within the two outer segments of the semi-flexible wall, while the inner segment is hollow. Rigid concrete cell foundations are located at each end, and the top of each rigid cell is fitted with a concrete thrust block, tieback anchors, and bearing pads.

A combination of solid elements (used near the ends of the span) and nonlinear beam elements are used to model the semi-flexible wall (Fig. 12). Specifically, longitudinal mild steel bars and prestressing tendons are modeled along the span length using discrete beam elements, which in turn, are positioned in accordance with structural plan sets. Also, solid elements are used to model the massive concrete portions of the rigid cell foundations, while the bearing pads and tieback anchors are modeled using beam elements. All mild steel rebar details, prestressing tendon details, and concrete cross sectional shapes are listed in [22]. Accurate nonlinear flexural behavior of the semi-flexible wall model was verified by comparing moment-curvature (M- $\Phi)$ data (computed from the FE model) to moment-curvature data calculated using an experimentally validated cross-sectional analysis software package [23].

\section{Finite Element Model Validation and Influence of Load-Measurement System 4.1 Load-Measurement System}

In December 1998, the USACE conducted a series of forty-two (42) full-scale 3x5 flotilla impact experiments against a rigid wall structure [2] at the Gallipolis Locks and Dam (now called 
the Robert C. Byrd Locks and Dam), located in Gallipolis Ferry, West Virginia. Later, in 2008, USACE conducted an additional series of twenty-three (23) full-scale $3 \times 3$ flotilla impact experiments against a semi-flexible wall structure at the Winfield Lock and Dam in Red House, West Virginia [13]. In both series of experiments, a custom-designed load-measurement system (Fig. 13) was affixed to the bow corner of the impacting barge in the test flotilla (either $3 \times 5$ or $3 \times 3$ in configuration) to enable measurement of impact forces. The load-measurement system consisted of a solid $229 \mathrm{~mm}$ (9 in) x $127 \mathrm{~mm}$ (5 in) curved steel beam, two $152 \mathrm{~mm}$ (6 in.) diameter bi-axial 1.78 MN (400 kip) clevis pin (or "shear pin”) load cells, and two clevis mounts. Each shear pin was inserted through one end of the curved steel beam (referred to as the 'load beam') and through a clevis mount, which was welded to the barge bow. Upon impact, force was transmitted from the load beam into the instrumented shear pins (where forces were measured), then into the clevis mounts, and finally, into the corner of the barge bow.

In the present study, data from two of the rigid wall experiments [2] and two of the semi-flexible wall experiments [13] are used to validate the accuracy of the flotilla FE models. Additionally, because the structural configuration, stiffness, and distribution of impact forces associated with the load beam (and the associated pins and clevis mounts) differ substantially from those of a typical, unmodified (i.e., un-instrumented) barge bow corner, it is of interest to determine whether impact forces measured through use of such a load beam differ significantly from impact forces generated by collision from an un-instrumented barge. If such differences are demonstrated and found to be significant, then there are important implications for the design of navigation guidance structures. Furthermore, if significant differences exist, then validation of the FE model can only be achieved if a representation of the load-measurement system itself is included in the barge model. 


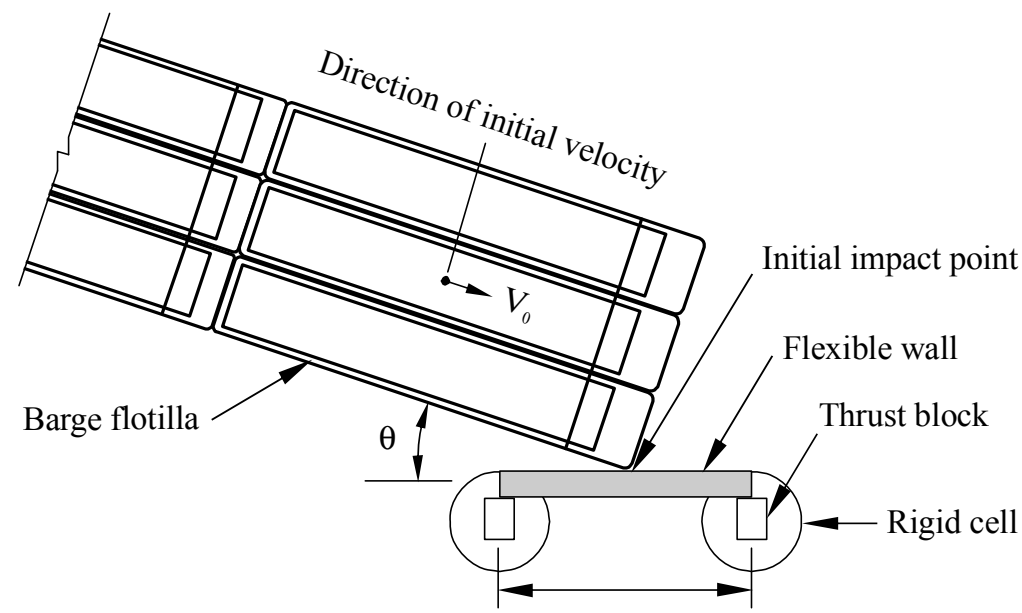

Single span of semi-flexible wall

a)

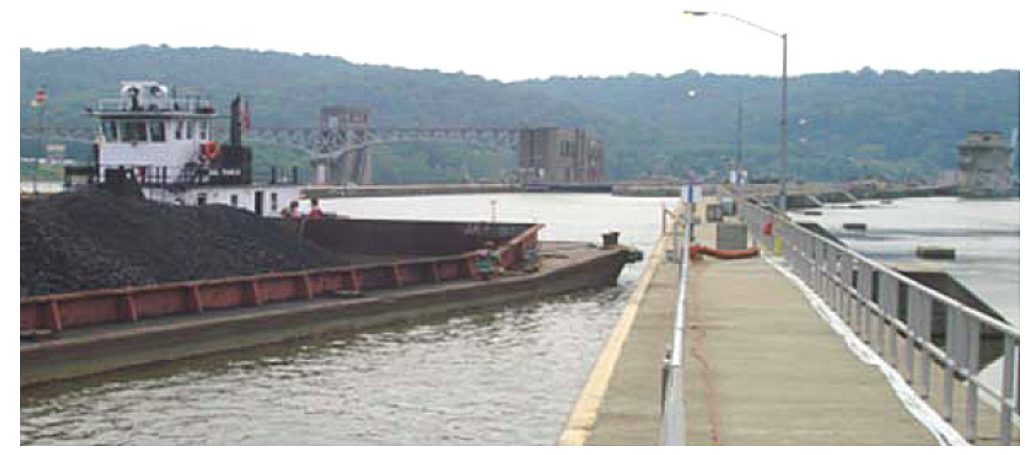

b)

Figure 11. Flotilla impacts on semi-flexible wall:

a) Schematic diagram, b) Experiments conducted at Winfield [21] 


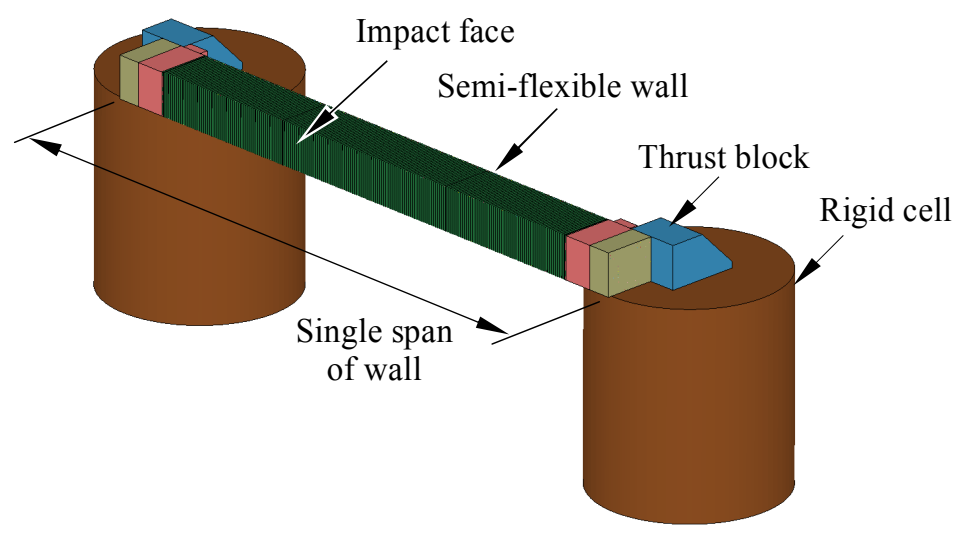

a)

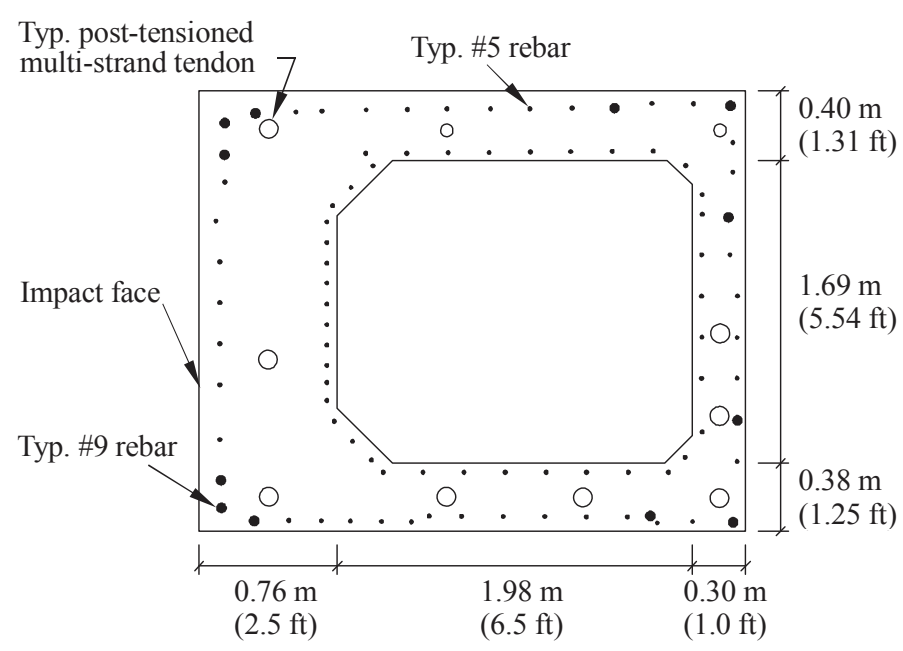

b)

Figure 12. Semi-flexible wall FE model:

a) Overall configuration (mesh not shown for clarity); b) Cross-section of semi-flexible wall beam

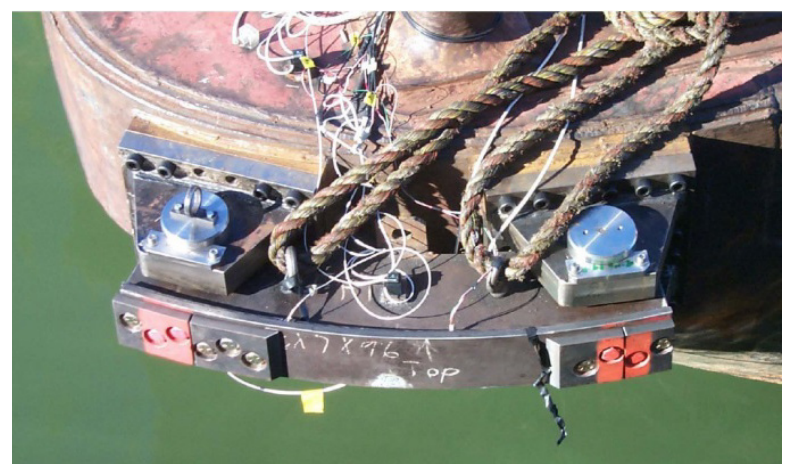

Figure 13. Load-measurement system (beam, shear pins, and clevis mounts) attached to bow corner of barge 
Accordingly, an FE model of the load-measurement system (Fig. 14a) is developed and integrated with the overall flotilla model for use in conducting validation impact simulations. Three-dimensional solid elements are used to model the geometry of the load beam and the two clevis mounts. The same strain-rate dependent nonlinear steel material model (detailed in [16]) that is used to model the barge is also used to represent the steel in the load beam and steel clevis mounts.

Rather than modeling the detailed geometry of the shear pins with solid elements, and employing computationally expensive contact definitions between the load beam, pins, and clevis mounts, a series of 'nodal rigid bodies' are instead used to emulate the function of the pins. In LS-DYNA modeling, a nodal rigid body consists of a collection of nodes that are constrained to move as a single rigid entity (i.e., the distances between nodes within the rigid body remain constant, even as the overall body translates and rotates). As illustrated in Fig. 14b-c, at each end of the load beam, a nodal rigid body is defined to tie (constrain) nodes within the footprint of the clevis pin to a single line of nodes lying inside the clevis mount. Each nodal line inside the clevis mounts corresponds to the hypothetical longitudinal axis of the corresponding shear pin. This modeling technique results in a computationally efficient means of allowing the end of the load beam to rotate within the clevis mesh in a way that emulates the rotation that would be permitted by the pin. Both clevis mounts are attached to the corner of the barge bow model (Fig. 14a) using translational constraints between nodes on the rear faces of the clevis mounts and the nearest corresponding nodes on the bow corner plate. 


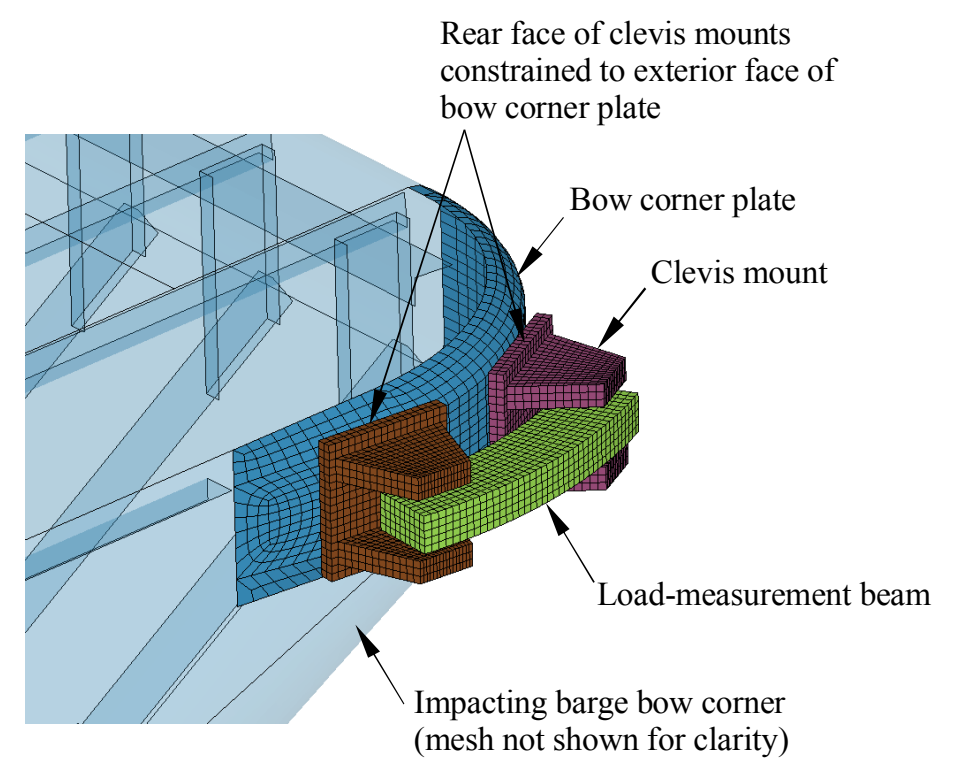

a)

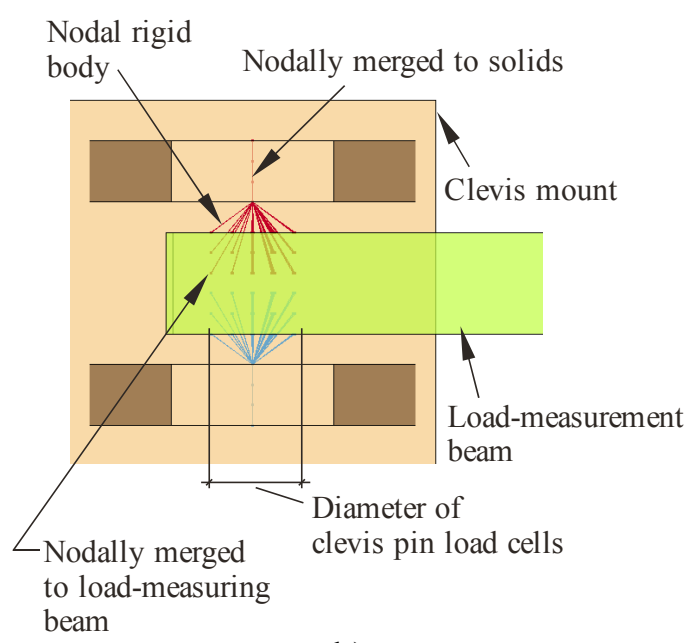

b)

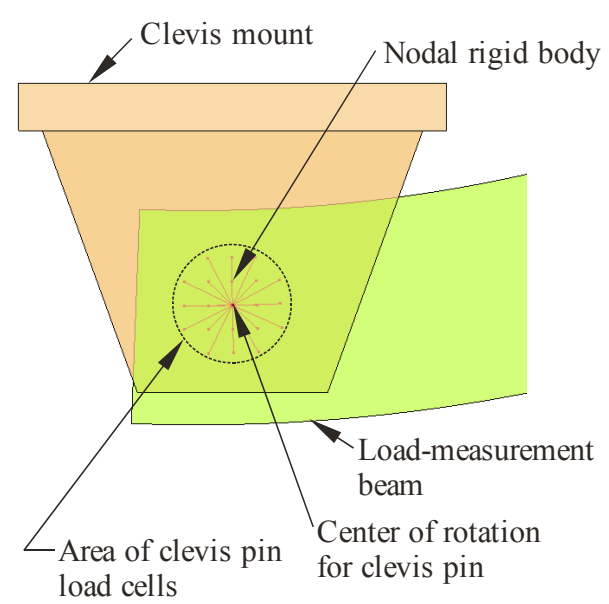

c)

Figure 14. Finite element model of load-measurement system:

a) Overview and attachment to barge; b) Elevation view of clevis and shear pin model; c) Plan view of clevis and shear pin model

\subsection{Model Validation Using Data from Rigid Wall Impact Experiments}

To assess the accuracy of the $3 \times 5$ flotilla model, Experiment 41 ( $3 \times 5$ flotilla, $9^{\circ}$ angle, 0.88 $\mathrm{m} / \mathrm{sec}, 2.9 \mathrm{ft} / \mathrm{sec}$, impact velocity) and Experiment 42 (3x5 flotilla, $18^{\circ}$ angle, $0.55 \mathrm{~m} / \mathrm{sec}, 1.8$ $\mathrm{ft} / \mathrm{sec}$, impact velocity) from the Robert C. Byrd Locks and Dam rigid wall test program [2] are 
simulated numerically. Each experiment is simulated with the load beam attached to the corner of the impacting barge so that direct comparisons between experiment and simulation can be made. Experimental and simulated impact forces acting perpendicular to the longitudinal axis of the wall are compared in Fig. 15. Peak impact force measured experimentally, using the load-measurement system pictured in Fig. 13, is $1.85 \mathrm{MN}$ (417 kip) for Experiment 41. Numerical impact simulation of the same condition, with inclusion of the load-measurement system FE model depicted in Fig. 14 , predicts an impact force of $1.60 \mathrm{MN}$ (360 kip) —approximately 14\% less than the experimental value. Regarding Experiment 42, the peak experimental impact force is $2.58 \mathrm{MN}$ (579 kip), whereas the numerical simulation predicts a force of $2.40 \mathrm{MN}$ (539 kip)-approximately 7\% less than the experimental value. Observed differences between the experimental test data and simulation results are attributed to physical phenomena and features present in the experimental tests that were not precisely reproduced in the numerical models. Examples include hydrodynamic effects acting on the flotilla; variability of lashing pre-tension levels; and variability of barge surface (friction) conditions. Overall, however, the level of agreement observed between the $3 \times 5$ flotilla experimental force data and corresponding simulation data is deemed acceptable for the purposes intended in the present study. 


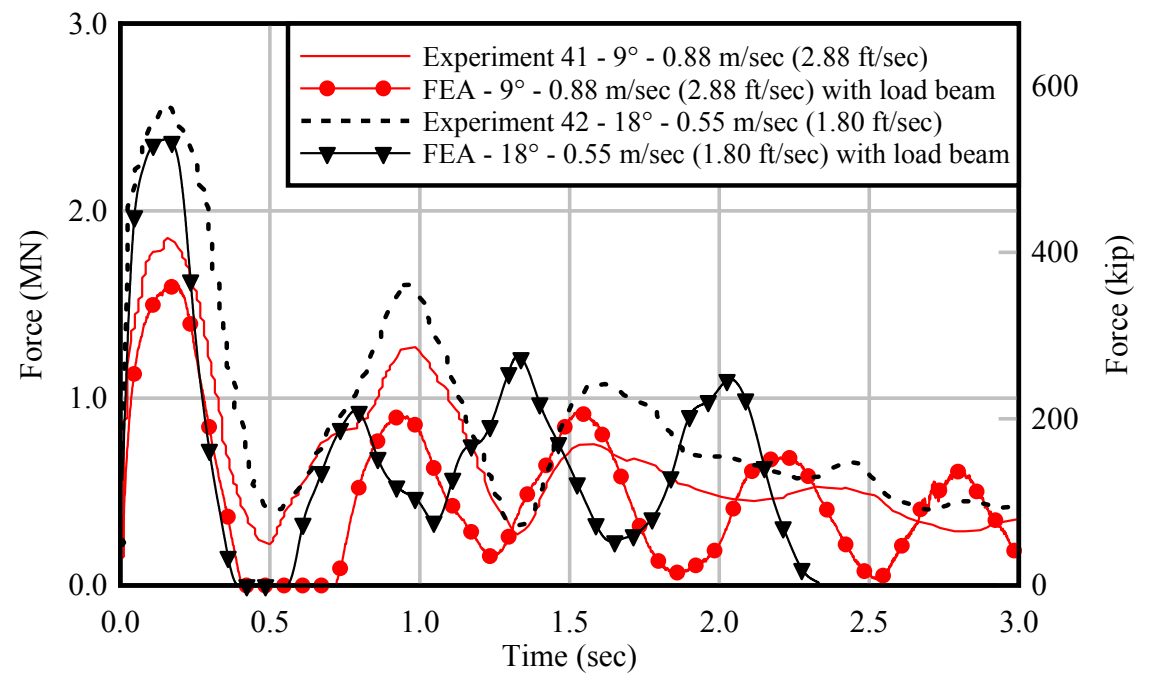

Figure 15. Time-histories of normal impact force for rigid wall Experiments 41 and 42 and corresponding FE simulations with load beam included

\subsection{Model Validation Using Data from Semi-flexible Wall Impact Experiments}

To assess the accuracy of the $3 \times 3$ flotilla model and the semi-flexible wall model described earlier, simulations of impact Experiment 10 (3x3 flotilla, $17^{\circ}$ angle, $0.88 \mathrm{~m} / \mathrm{sec}, 2.88 \mathrm{ft} / \mathrm{sec}$, impact velocity) and Experiment 20 (3x3 flotilla, $13.6^{\circ}$ angle, $0.82 \mathrm{~m} / \mathrm{sec}, 2.69 \mathrm{ft} / \mathrm{sec}$, impact velocity) from the Winfield Lock and Dam test program [13] are numerically simulated. Each experiment is simulated with the load beam attached to the corner of the impacting barge bow. Comparative plots of impact forces, measured experimentally and computed from FE impact simulations, are shown in Fig. 16. Peak impact force measured experimentally, using the load-measurement system pictured in Fig. 13, is $2.30 \mathrm{MN}$ (517 kip) for Experiment 10. Numerical impact simulation of the same condition, with inclusion of the load-measurement system FE model depicted in Fig. 14, predicts an impact force of $2.54 \mathrm{MN}$ (571 kip)—approximately 10\% greater than the experimental value. Regarding Experiment 20, the peak experimental impact force is $1.83 \mathrm{MN}$ (411 kip), whereas the numerical simulation predicts a force of $1.99 \mathrm{MN}$ (448 kip) — approximately $10 \%$ greater than the experimental value. In [13], additional comparisons of experimentally measured wall deflection data and corresponding FE deflection data are shown to 
be similar with regard to agreement level (both in terms of magnitude and frequency of oscillation). As noted earlier, observed differences between experimental test data and simulation results are attributed to experimental phenomena and features not precisely reproduced in the numerical models. In addition to the physical phenomena listed in the previous section, deviations evident in Fig. 16 are also likely due to differences between actual structural damping in the semi-flexible wall that was tested, and the $5 \%$ of critical damping that was assumed in the simulations. Overall, however, based on the level of agreement between test data and simulation data, the $3 \times 3$ flotilla model and the semi-flexible wall model are deemed to be of acceptable accuracy for use in the present study.

\subsection{Influence of Load Beam on Measured and Computed Impact Forces}

To investigate whether the structural characteristics of the load-measurement beam used in the USACE experimental test programs significantly influenced the measured barge impact forces, the semi-flexible wall validation impact conditions discussed above (Experiment 10 and 20) are re-simulated, however, this time with the load beam omitted from the flotilla model. In these simulations, the un-instrumented bow corner of the impacting barge FE model—rather than the load beam-makes contact with the wall, and therefore the forces computed are more representative of 'realistic' (i.e., un-instrumented) barge impact conditions. 


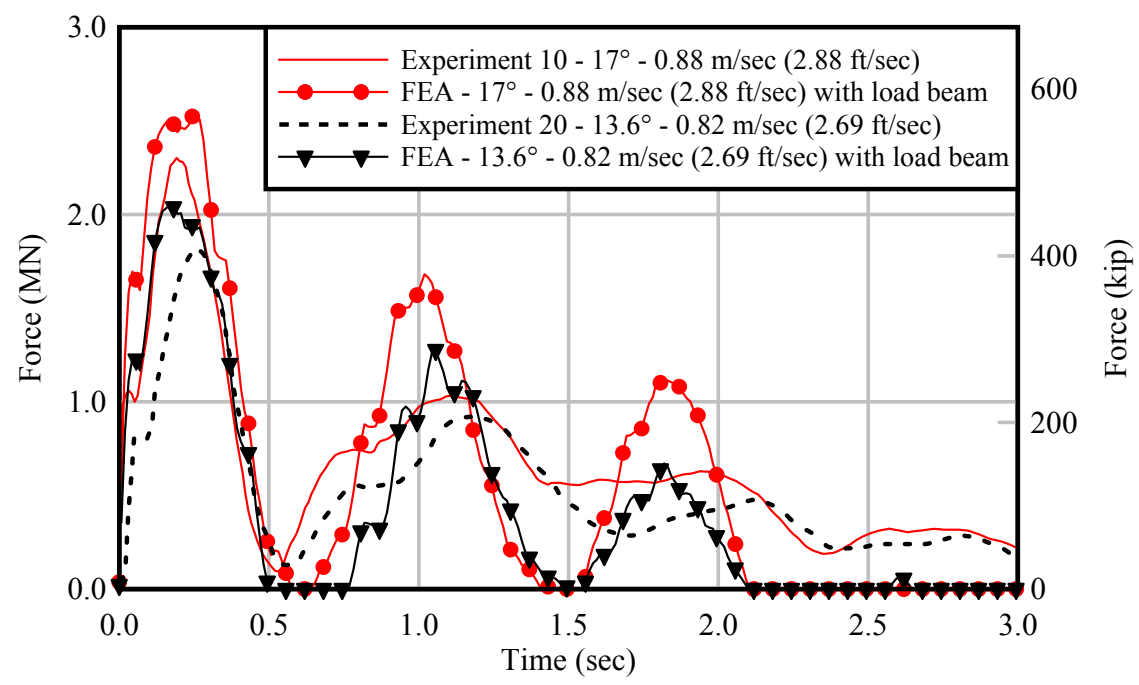

Figure 16. Time-histories of normal impact force for semi-flexible wall Experiments 10 and 20 and corresponding FE simulations with load beam included

In Fig. 17, FE impact forces computed with and without the load-measurement beam are compared. For the Experiment 10 conditions, peak impact forces are $2.54 \mathrm{MN}$ (571 kip) with the load beam (instrumented) and 1.89 MN (426 kip) without (un-instrumented). For the Experiment 20 conditions, peak impact forces are 1.99 MN (448 kip) with the load beam and 1.57 MN (353 kip) without. Hence, peak impact forces determined using an instrumented barge (with a load-measurement beam) are found to be considerably greater-by approximately $20 \%$ to $25 \%$ - than those generated by an un-instrumented barge under the same impact conditions (flotilla size, impact speed, impact angle). Observed increases in impact force are consistent with the fact that the stiffness of the load beam is greater than the stiffness of a typical un-instrumented barge bow corner. Importantly, this finding indicates that unnecessary conservatism could be unintentionally introduced into impact loads specified in design standards, if such standards are developed strictly based on experimental forces measured using devices such as the load-measurement system (recall Fig. 13). 


\section{Parametric Study of Barge Impacts Against Wall Structures}

To quantify flotilla impact forces over a range of different impact conditions that would typically be considered infeasible to investigate via experimental testing, a FE parametric study is conducted using the flotilla and wall models described and validated above. Impact force sensitivities to flotilla size, impact speed, impact angle, and wall type are discussed. For additional discussions of impact force sensitivity to parameters such as lashing pretension level and concrete strength, see [16] and [22].

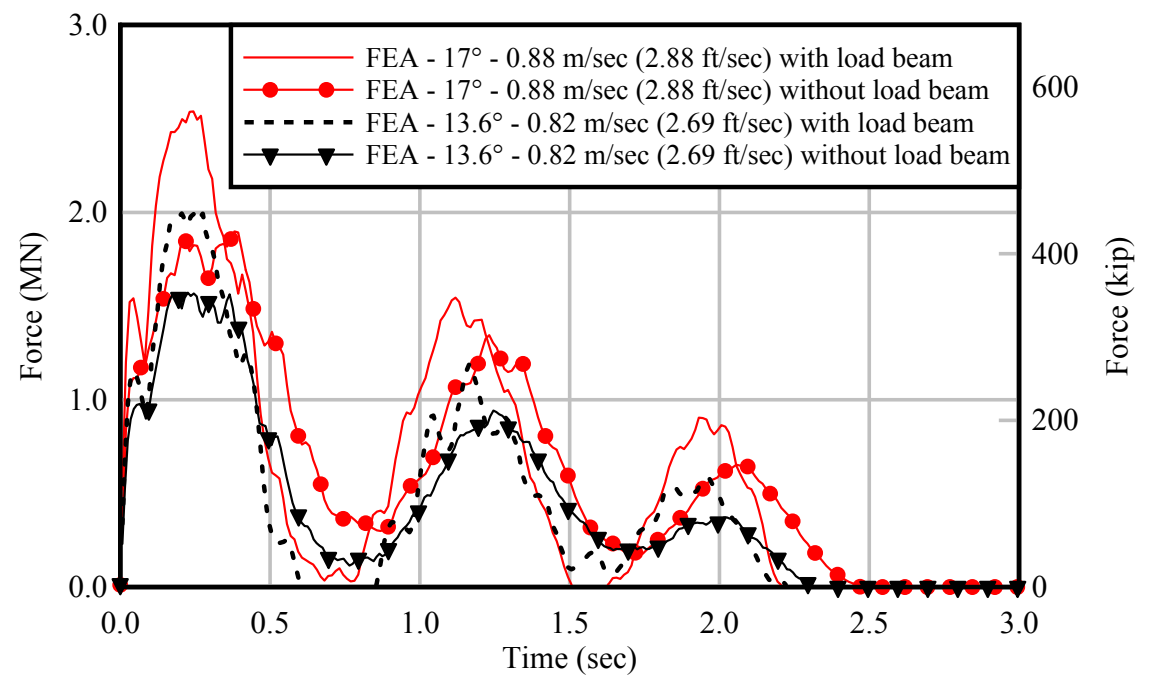

Figure 17. Comparison of force time-histories for FE simulations of Experiments 10 and 20 with load beam (instrumented) and without (un-instrumented)

\subsection{Simulated Impact Conditions}

Using the $3 \times 3$ and $3 \times 5$ flotilla FE models and the rigid and semi-flexible wall FE models discussed above, numerical simulations of the thirty-five (35) impact conditions summarized in Table 1 are conducted. A key objective in conducting these simulations is to quantify peak impact forces for collisions from typical (i.e., un-instrumented) commercial barge flotillas, thus all simulations are conducted using flotilla models that exclude the load beam. Impact angles and speeds are selected to span the range of probable impact conditions that occur on lock approach walls. For selected cases, identical impact angles and speeds are used in simulations of both $3 \times 3$ 
and $3 \times 5$ flotillas so that the influence of flotilla size on impact force can be isolated and quantified.

Finally, each impact simulation is carried out (through time) until both a zero impact force is achieved and the velocity vector of the flotilla indicates movement away from the wall, thereby indicating impact has ceased and subsequent barge-wall contact is unlikely.

Table 1. Parametric FE study of flotilla impacts on rigid walls (20 cases) and semi-flexible walls (15 cases)

\begin{tabular}{|c|c|c|c|c|c|c|}
\hline $\begin{array}{l}\text { Flotilla } \\
\text { size }\end{array}$ & $\begin{array}{l}\text { Impact } \\
\text { angle, }\end{array}$ & $\begin{array}{c}\text { Impact } \\
\text { velocity } \\
\mathrm{m} / \mathrm{sec},(\mathrm{ft} / \mathrm{sec})\end{array}$ & $\begin{array}{c}\text { Rigid } \\
\text { wall }\end{array}$ & $\begin{array}{l}\text { Semi- } \\
\text { flexible } \\
\text { wall }\end{array}$ & $\begin{array}{l}\text { Peak rigid wall } \\
\text { impact force } \\
\text { MN (kip) }\end{array}$ & $\begin{array}{c}\text { Peak semi-flexible } \\
\text { wall impact force } \\
\text { MN (kip) }\end{array}$ \\
\hline $3 \times 3$ & 10 & $0.30(1.0)$ & $\checkmark$ & & $0.65(146)$ & \\
\hline $3 \times 3$ & 10 & $0.61(2.0)$ & & $\checkmark$ & & $1.02(229)$ \\
\hline $3 \times 3$ & 10 & $0.91(3.0)$ & & $\checkmark$ & & $1.23(276)$ \\
\hline $3 \times 3$ & 10 & $1.22(4.0)$ & & $\checkmark$ & & $1.39(313)$ \\
\hline $3 \times 3$ & 20 & $0.91(3.0)$ & $\checkmark$ & $\checkmark$ & $2.13(478)$ & $2.15(483)$ \\
\hline $3 \times 3$ & 20 & $1.22(4.0)$ & & $\checkmark$ & & $2.65(595)$ \\
\hline $3 \times 3$ & 20 & $1.52(5.0)$ & & $\checkmark$ & & $2.93(658)$ \\
\hline $3 \times 3$ & 30 & $0.91(3.0)$ & & $\checkmark$ & & $3.46(778)$ \\
\hline $3 \times 3$ & 30 & $1.52(5.0)$ & $\checkmark$ & $\checkmark$ & $3.80(855)$ & $4.03(906)$ \\
\hline $3 \times 5$ & 10 & $0.30(1.0)$ & $\checkmark$ & & $0.74(167)$ & \\
\hline $3 \times 5$ & 10 & $0.61(2.0)$ & $\checkmark$ & $\checkmark$ & $1.08(242)$ & $1.02(229)$ \\
\hline $3 \times 5$ & 10 & $0.91(3.0)$ & $\checkmark$ & $\checkmark$ & $1.25(282)$ & $1.24(278)$ \\
\hline $3 \times 5$ & 10 & $1.22(4.0)$ & $\checkmark$ & & $1.42(320)$ & \\
\hline $3 \times 5$ & 10 & $1.52(5.0)$ & $\checkmark$ & & $1.58(355)$ & \\
\hline $3 \times 5$ & 20 & $0.30(1.0)$ & $\checkmark$ & & $1.34(301)$ & \\
\hline $3 \times 5$ & 20 & $0.61(2.0)$ & $\checkmark$ & $\checkmark$ & $1.72(387)$ & $1.68(378)$ \\
\hline $3 \times 5$ & 20 & $0.91(3.0)$ & $\checkmark$ & $\checkmark$ & $2.14(481)$ & 2.19 (492) \\
\hline $3 \times 5$ & 20 & $1.22(4.0)$ & $\checkmark$ & $\checkmark$ & $2.70(607)$ & $2.66(598)$ \\
\hline $3 \times 5$ & 20 & $1.52(5.0)$ & $\checkmark$ & & $2.90(652)$ & \\
\hline $3 \times 5$ & 25 & $0.91(3.0)$ & $\checkmark$ & & $2.79(627)$ & \\
\hline $3 \times 5$ & 30 & $0.15(0.5)$ & $\checkmark$ & & $1.20(269)$ & \\
\hline $3 \times 5$ & 30 & $0.30(1.0)$ & $\checkmark$ & & $1.57(353)$ & \\
\hline $3 \times 5$ & 30 & $0.61(2.0)$ & $\checkmark$ & & 2.44 (549) & \\
\hline $3 \times 5$ & 30 & $0.91(3.0)$ & $\checkmark$ & & $3.45(775)$ & \\
\hline $3 \times 5$ & 30 & $1.22(4.0)$ & $\checkmark$ & $\checkmark$ & $3.77(848)$ & $3.70(831)$ \\
\hline $3 \times 5$ & 30 & $1.52(5.0)$ & $\checkmark$ & $\checkmark$ & $3.81(857)$ & $3.92(881)$ \\
\hline
\end{tabular}




\subsection{Rigid Wall Simulation Results}

Impact forces for lower bound $\left(10^{\circ}, 0.30 \mathrm{~m} / \mathrm{sec}, 1.0 \mathrm{ft} / \mathrm{sec}\right)$ and upper bound $\left(30^{\circ}\right.$, $1.52 \mathrm{~m} / \mathrm{sec}, 5.0 \mathrm{ft} / \mathrm{sec}$ ) rigid wall impact simulations are shown in Fig. 18 for the $3 \times 3$ and $3 \times 5$ flotillas. In the lower bound case, the shallow angle and low impact speed minimize flotilla momentum that is directed 'at' (i.e., normal to) the wall. Conversely, in the upper bound case, the steeper angle and higher impact speed maximize flotilla momentum directed at the wall. Since the wall structure modeled in these simulations is infinitely rigid, the observed oscillations in force time-history data are not related to wall deflection. Instead, such oscillations are the result of interactions between the crushable barge bow corner and the wall (as the flotilla is redirected) and also dynamic flexing (i.e., bending) of the overall flotilla. Deformation associated with flotilla flexing is concentrated at the barge-to-barge interfaces and primarily involves tensile elongation of the wire-rope lashings.

Importantly—and relating to the concept of flotilla flexing-Fig. 18 also indicates that peak impact forces in both the lower and upper bound cases are effectively invariant with respect to flotilla length. That is, for a given impact angle and speed, increasing the flotilla size (and therefore also mass and momentum) from $3 \times 3$ to $3 \times 5$ lengthens the duration of the impact loading, but does not produce appreciably different peak impact forces. An explanation for this observation and discussion of the associated design implications are provided later. Impact conditions involving intermediate impact angles, impact speeds, and levels of momentum directed at the wall generally produce force data (detailed in [16]) that fall between the bounding curves shown in Fig. 18. 


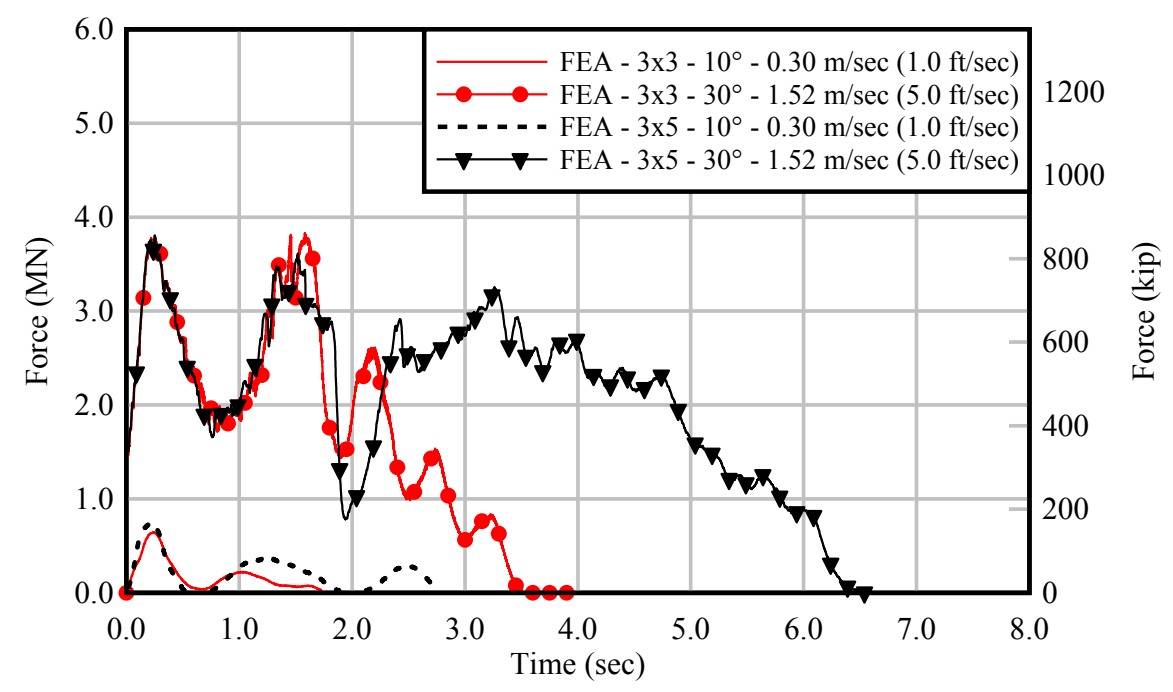

Figure 18. Force time-histories for $3 \times 3$ and $3 \times 5$ flotilla impact simulations on rigid wall

\subsection{Semi-Flexible Wall Simulation Results}

Impact forces for low momentum $\left(10^{\circ}, 0.61 \mathrm{~m} / \mathrm{sec}, 2.0 \mathrm{ft} / \mathrm{sec}\right)$ and high momentum $\left(30^{\circ}\right.$, $1.52 \mathrm{~m} / \mathrm{sec}, 5.0 \mathrm{ft} / \mathrm{sec}$ ) semi-flexible wall impact simulations are shown in Fig. 19 for flotilla sizes of $3 \times 3$ and $3 \times 5$. Unlike the rigid wall cases discussed earlier, the semi-flexible impact cases involve a wall that possesses finite (rather than infinite) stiffness, therefore the wall undergoes deflection during impact loading. However, the overall oscillations exhibited among the Fig. 19 force data still relate primarily to dynamic flexing and redirection of the flotillas, not to dynamic wall response. Supporting this assertion is the fact that the damped natural period of oscillation of the semi-flexible wall structure is on the order of approximately $0.28 \mathrm{sec}[22]$ - far less than the dominant period of force oscillation evident among the Fig. 19 force data (which is greater than 1 sec). Additionally, peak impact forces shown in Fig. 19 are once again effectively invariant with respect to flotilla size, as was the case in the rigid wall results. For a given impact angle and speed, increasing the flotilla size from $3 \times 3$ to $3 \times 5$ lengthened the duration of the impact loading, but did not lead to appreciable changes in peak impact forces. 


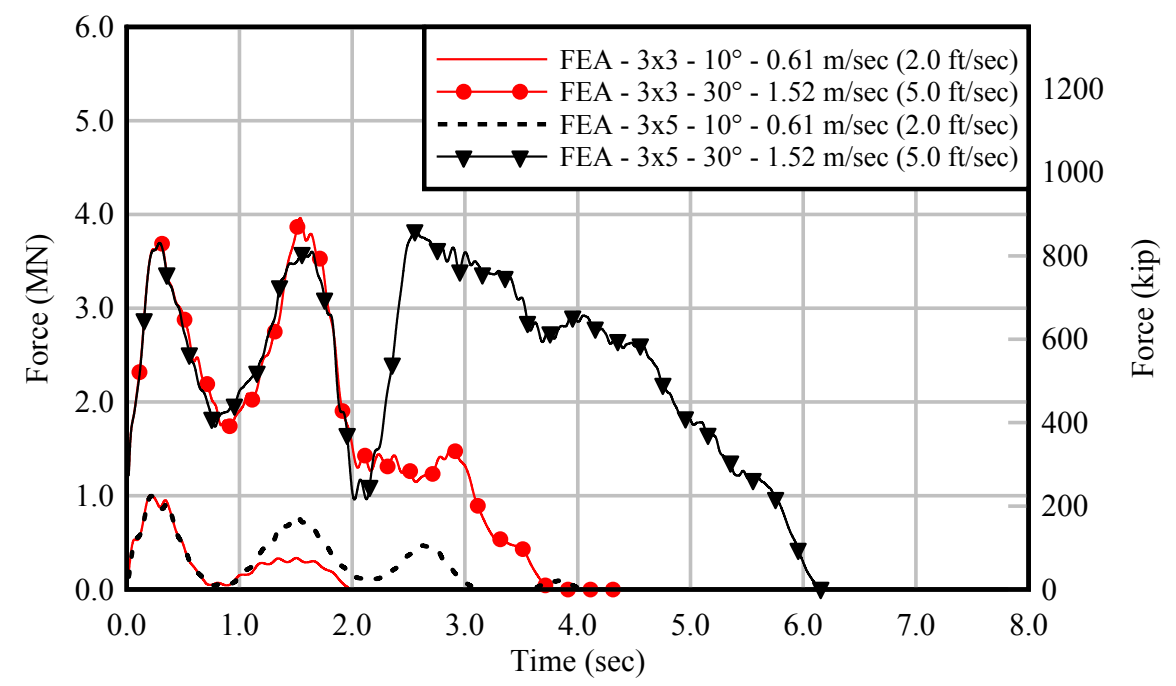

Figure 19. Force time-histories for impact simulations on semi-flexible wall

\section{Discussion of Results}

\subsection{Flexural Behavior of Barge Flotillas During Oblique Impacts}

Among the impact conditions listed in Table 1, there are several 'paired' $(3 \times 3$ and $3 \times 5)$ conditions for which impact speed and impact angle are identical. Data obtained from impact simulations of the paired conditions can be used to isolate the influence that flotilla size (specifically, the number of rows) has on impact force. For example, force results from paired (3x3 and 3x5) semi-flexible wall impact conditions (Table 2) reveal important relationships between flotilla size (number of rows), flotilla momentum (normal to wall), and peak impact force (normal to wall).

When the $3 \times 3$ and $3 \times 5$ flotilla force data are considered independently of one another (i.e., scanning vertically down along each column of force data in Table 2): increases of impact speed and/or impact angle are positively correlated with increases of peak impact force, as expected. However, when comparisons are made between forces generated by differing flotilla sizes ( $3 \times 3$ vs. $3 \times 5)$ impacting at the same angle and speed (i.e., scanning horizontally along each row of force data in Table 2), the results are unexpected and, in fact, contrary to assumptions made in typical 
design standards (e.g., [1]). Design standards typically assume that peak impact force is proportional to the total momentum of the entire flotilla. Thus, a $3 \times 5$ flotilla traveling at the same speed and angle as a $3 \times 3$ flotilla would be expected to generate a larger impact force due to the increase in mass (5 rows of barges instead of 3) and the corresponding increase of total flotilla momentum. As indicated by the data in Table 2, peak impact forces produced by $3 \times 3$ and $3 \times 5$ flotillas are nearly identical (differing by $3 \%$ or less) for instances where angle and speed are identical.

Table 2. Results from paired ( $3 \times 3$ and $3 \times 5)$ flotilla impacts against the semi-flexible wall

\begin{tabular}{|c|c|c|c|}
\hline \multirow{2}{*}{$\begin{array}{l}\text { Impact condition } \\
\text { (angle }{ }^{\circ} \text {, speed: } \mathrm{m} / \mathrm{sec}, \mathrm{ft} / \mathrm{sec} \text { ) }\end{array}$} & \multicolumn{3}{|c|}{ Normal impact force (MN, kip) } \\
\hline & $3 \times 3$ flotilla & $3 \times 5$ flotilla & Percent difference \\
\hline $10^{\circ}-0.61(2.0)$ & $1.02(229)$ & $1.02(229)$ & $(+0 \%)$ \\
\hline $10^{\circ}-0.91(3.0)$ & $1.23(276)$ & $1.24(278)$ & $(+1 \%)$ \\
\hline $20^{\circ}-0.91(3.0)$ & $2.15(483)$ & $2.19(492)$ & $(+2 \%)$ \\
\hline $20^{\circ}-1.22(4.0)$ & $2.65(595)$ & $2.66(598)$ & $(+1 \%)$ \\
\hline $30^{\circ}-1.52(5.0)$ & $4.03(906)$ & $3.92(881)$ & $(-3 \%)$ \\
\hline
\end{tabular}

The fact that an increase in the number of barge rows in a flotilla does not produce a proportional increase in impact force, while unexpected, can be understood by considering the longitudinal flexibility of multiple-row flotillas. In shallow-angle 'glancing' (re-directional) impact scenarios, peak impact force on the wall generally occurs during the initial force pulse (i.e., the pulse associated with initial contact between the flotilla and wall). During this phase, only the lead row of the flotilla is redirected by the wall. This behavior is clearly evident in the FE simulation results. For example, Fig. 20 presents flotilla deformations (i.e., flotilla 'flexing') for $3 \times 3$ and $3 \times 5$ flotillas at time $t=0.4 \mathrm{sec}$ (i.e., when peak impact force occurs for the $20^{\circ}, 0.91 \mathrm{~m} / \mathrm{sec}$, $3 \mathrm{ft} / \mathrm{sec}$, impact condition). At the point of peak force generation, only the lead row in each flotilla $(3 \times 3$ and $3 \times 5)$ is significantly redirected, and the trailing rows remain essentially un-rotated. 
Isolated redirection of the lead row is possible due to the flexibility of the wire-rope lashings that connect barge rows together.

As a consequence of the isolated - albeit transient_-lead row redirection, peak impact force is found to be most strongly (and positively) correlated not to the momentum of the entire flotilla, but rather to the momentum of just the lead row. In Fig. 21, plots of the 'paired' semi-flexible data (listed in Table 2) reveal a relatively disperse correlation between force and total momentum (Fig. 21a). In contrast, a very strong, low-dispersion correlation is present between force and lead row momentum (Fig. 21b). Furthermore, when data for all of the rigid wall and semi-flexible wall simulations listed in Table 1 are plotted in this same manner (Fig. 22), a clear correlation between peak impact force and lead row momentum emerges, despite variations of flotilla size, impact angle, impact speed, and wall type.

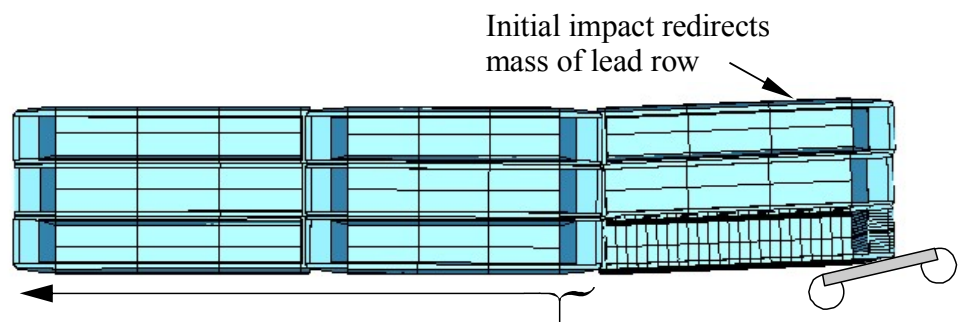

Additional (trailing) rows of flotilla make no contribution to initial (and maximum) impact force

a)

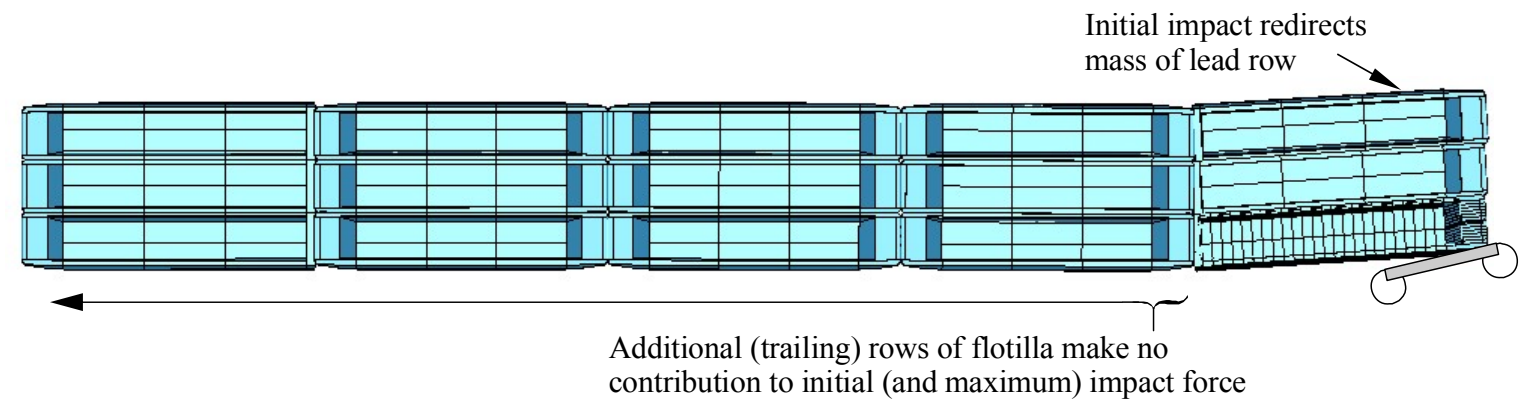

b)

Figure 20. Barge flotilla deformation at peak force for impact condition $20^{\circ}$ and $0.91 \mathrm{~m} / \mathrm{sec}, 3.0$ $\mathrm{ft} / \mathrm{sec}$, (displacements scaled by factor of 50): a) $3 \times 3$ flotilla; b) $3 \times 5$ flotilla 


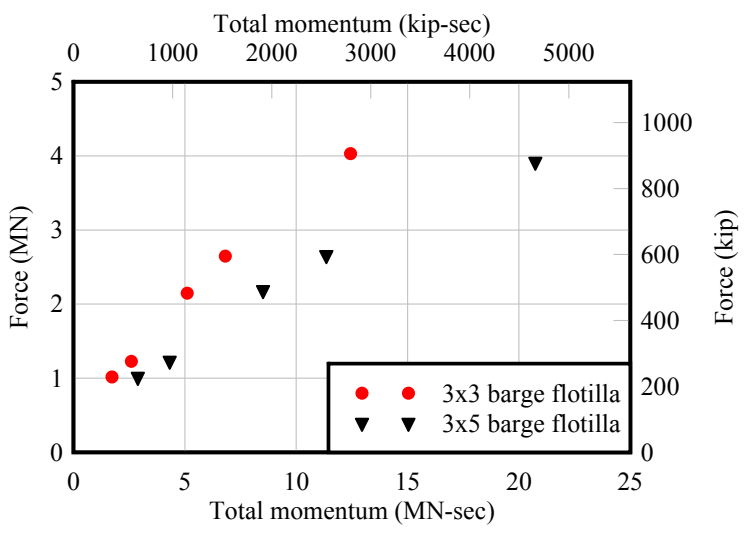

a)

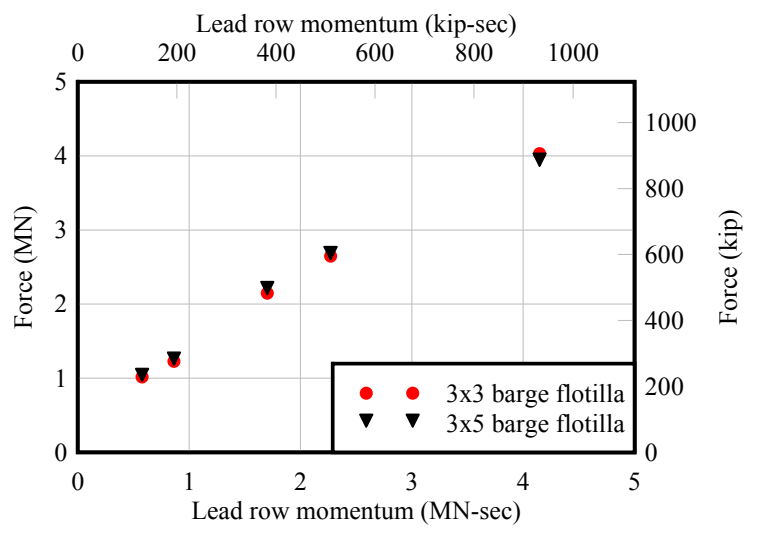

b)

Figure 21. Peak flotilla impact forces on semi-flexible wall as a function of:

a) Momentum of entire flotilla; b) Momentum of lead row only

(Note: all force and momentum quantities are normal to wall)

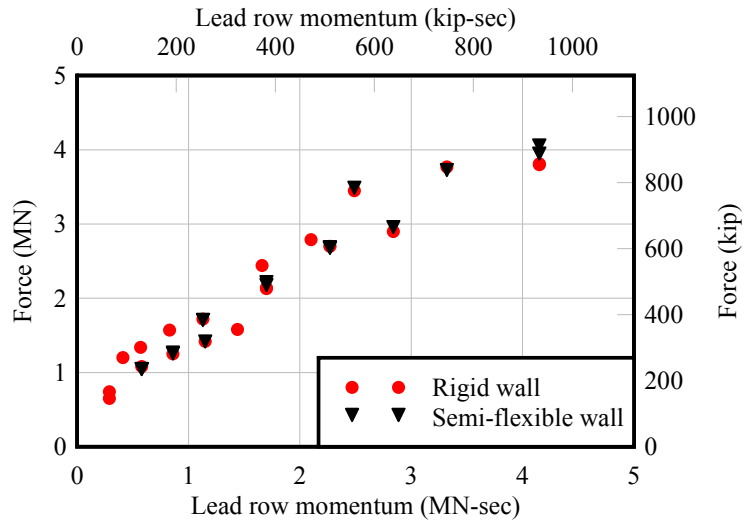

Figure 22. Peak impact forces for all rigid wall and semi-flexible wall FE simulations listed in Table 1 (Note: all force and momentum quantities are normal to wall)

Additional parametric simulations [22], not included here due to space constraints, have also confirmed that impact forces vary with respect to the number of barge columns present in the lead row of the flotilla. Thus, for example, a flotilla with three columns across the width of the lead row (e.g., a 3x3) produces significantly greater impact force than a flotilla with a single column (e.g., a 1x3; recall Fig. 1) impacting at the same angle and speed. 


\subsection{Comparison of Rigid Wall Impact Simulation Results to USACE ETL 563 Expression}

The USACE document ETL 563 [1], which was derived from data collected during the USACE rigid wall experimental test program [2], provides structural designers with an empirically-derived equation for computing barge flotilla forces for "rigid navigation structures such as lock walls, approach walls, channel walls, revetments, and coastal structures." Design guidance provided in ETL 563 is applicable to shallow angle $\left(0^{\circ} \leq \theta<30^{\circ}\right)$ glancing (i.e., re-directional) impacts where the impact force, resolved normal to the surface of the wall, does not exceed 3.56 MN (800 kip). When it is anticipated that impact forces can exceed 3.56 MN (800 kip), additional guidance must be sought in quantifying design impact loads. When applicable, the ETL 563 force prediction equation relates normal impact force to the component of total flotilla momentum that is directed at (i.e., normal to) the wall. Expressed in U.S. customary units (as provided in ETL 563), the force prediction equation is:

$$
F_{m}=0.435 \cdot m \cdot\left(V_{0 x} \cdot \sin \theta+V_{0 y} \cdot \cos \theta\right) \leq 800 \mathrm{kip}
$$

where $F_{m}$ is the maximum impact force normal to the wall (kip); $m$ is the total mass of the flotilla $\left(\mathrm{kip}-\mathrm{sec}^{2} / \mathrm{ft}\right) ; V_{0 x}$ is the component of impact speed parallel to the barge columns ( $\left.\mathrm{ft} / \mathrm{sec}\right) ; V_{0 y}$ is the component of impact speed parallel to the barge rows ( $\mathrm{ft} / \mathrm{sec})$; and, $\theta$ is the impact angle.

In Fig. 23, forces computed from the FE rigid wall impact simulations (20 cases, recall Table 1) are compared to ETL 563 force predictions computed using Eqn. (2). At low-momentums (less than $\sim 5.0 \mathrm{MN}-\mathrm{sec}[\sim 1000$ kip-sec]), which could be considered representative of service-level impact conditions, the empirical ETL 563 equation exhibits a reasonable level of conservatism relative to the FE results. However, over a broad range of higher-momentums-i.e., the types of conditions that often control the structural design of walls - the empirical ETL 563 
equation is found to be undesirably conservative. It is worth noting that in the USACE rigid wall impact test program [2] that formed the basis for ETL 563, the range of experimentally tested momentums (resolved normal to the wall) spanned a relatively narrow range: from approximately 2.5 MN-sec ( $\sim 550 \mathrm{kip}-\mathrm{sec})$ to $5.0 \mathrm{MN}-\mathrm{sec}$ ( $\sim 1000 \mathrm{kip}-\mathrm{sec})$, primarily due to physical testing constraints. Per [2], best-fit linear regression was then applied to the test data to yield Eqn. (2). Recalling the favorable agreement that was previously demonstrated between FE simulation results and data from USACE rigid wall Experiments 41 and 42 (Fig. 15), the conservatism of ETL 563 relative to the FE results (Fig. 23) is likely due to the narrow range of momentums that were feasible to achieve during physical testing, and the influence of the load-measurement system (load beam) that was employed. It is suggested that future design implementation of the FE force data computed in the present study, in lieu of the ETL 563 equation, could lead to significant reductions in design loads for walls, and in turn, potential savings in construction costs.

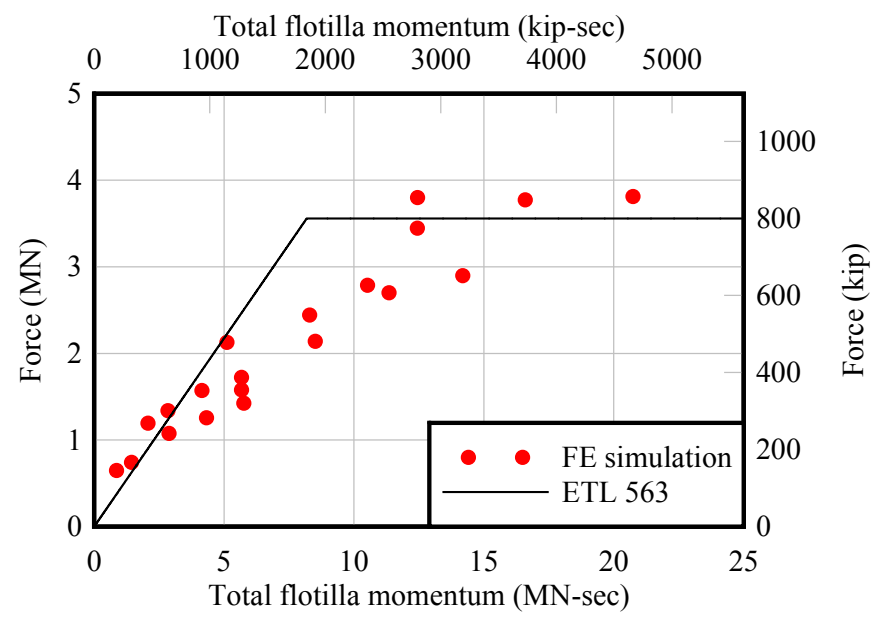

Figure 23. Comparison of FE results for rigid wall simulations listed in Table 1 (20 cases) and ETL 563 (Note: all force and momentum quantities are normal to wall)

\section{Conclusions}

Current practice in the U.S. for designing rigid and semi-flexible waterway structures to resist barge impact loading involves the use of a conservative, empirical force determination 
procedure. Conservatism built into this procedure stems from the limited availability of barge flotilla impact force data, and supplementation of such data is needed to inform and refine the relevant design guidelines. As a substitute for costly and potentially infeasible physical experimentation, parametric sets of impact forces have been generated and cataloged as part of the present study through nonlinear dynamic FE simulation of collisions between barge flotillas and wall structures.

The flotilla models contain barges with one-to-one representations of structural members and member connections, inter-barge contact interactions, and inter-barge wire-rope lashings. Both rigid and semi-flexible concrete wall structures have also been modeled, where these structures correspond, respectively, to walls used in full-scale impact experiments previously conducted by the USACE at two different lock and dam sites. Force time-history data gathered during the USACE impact experiments have been used to: 1) characterize the influence of load-measurement systems used during the physical tests; and, 2) successfully validate peak impact forces from FE simulations of collisions between flotillas and rigid walls, and separately, flotillas and semi-flexible walls.

Following validation, a parametric set of 35 dynamic, nonlinear FE impact simulations were conducted on the rigid ( 15 cases) and semi-flexible ( 20 cases) wall models using both $3 \times 3$ and $3 \times 5$ flotilla models, and where both initial flotilla speeds and approach angles were varied. By comparing data from across the full parametric set of simulation results (representing un-instrumented barge impacts on rigid and semi-flexible walls), it was determined that peak impact forces are primarily a function of the mass contained within the lead (i.e., foremost) row of barges in the flotilla, not the mass of the entire flotilla. 
Finite element simulation data have also been compared to impact force data computed using the USACE rigid structure design guidance document ETL 563. These comparisons demonstrate that over a wide range of impact momentums, the ETL 563 design guideline predicts conservative impact forces in comparison to respective FE simulation data. Collectively, the findings of this study hold important implications for future development of updated impact load prediction procedures for use in the design of navigational wall structures. Specifically, the recommendation to rely on lead-row flotilla momentum as the predictor of impact force may lead to more accurate and economical designs.

\section{Acknowledgements}

The authors thank the U.S. Army Corps of Engineers for providing the funding that made this research possible. The authors also gratefully acknowledge Zachary S. Harper for contributions made to the development of the barge flotilla finite element models and John R. Wilkes for modeling and impact simulation support provided.

\section{References}

[1] U.S. Army Corps of Engineers, Barge Impact Analysis for Rigid Walls, Engineer Technical Letter 1110-2-563, U.S. Army Corps of Engineers, Washington D.C., 2004.

[2] Patev, R.C., Barker, B.C., and Koestler III, L.V., Full-Scale Barge Impact Experiments, Robert C. Byrd Lock and Dam, Gallipolis Ferry, West Virginia, U.S. Army Corps of Engineers Research and Development Center, ERDC/ITL TR-03-7, Vicksburg, MS, 2003.

[3] American Association of State Highway and Transportation Officials (AASHTO), Guide Specifications and Commentary for Vessel Collision Design of Highway Bridges, 2nd Edition, AASHTO, Washington D.C., 2009. 
[4] European Committee for Standardization (CEN). Eurocode 1: Actions on Structures - Part 1-7: General Actions - Accidental Actions (EN 1991-1-7:2007-02), CEN, Brussels, 2007.

[5] Fan, W. and Yuan, W., "Numerical Simulation and Analytical Modeling of Pile-Supported Structures Subjected to Ship Collisions including Soil-Structure Interaction", Ocean Engineering, 91:11-27, 2014.

[6] Fan, W., Liu, Y., Liu, B., and Guo, W., "Dynamic Ship-Impact Load on Bridge Structures Emphasizing Shock Spectrum Approximation”, ASCE Journal of Bridge Engineering, $04016057,2016$.

[7] Yuan, P., Harik, I.E., and Davidson M.T., Multi-Barge Flotilla Impact Forces on Bridges, Kentucky Transportation Center Report KTC-08-13/SPR261-03-2F, University of Kentucky, Lexington, 2008.

[8] Consolazio, G.R., Davidson, M.T., and Cowan, D.R., "Barge Bow Force-Deformation Relationships for Barge-Bridge Collision Analysis", Transportation Research Record, Journal of the Transportation Research Board, 2009.

[9] Consolazio, G.R., and Cowan, D.R., "Numerically Efficient Dynamic Analysis of Barge Collisions with Bridges Piers", ASCE Journal of Structural Engineering, 131(8):1256-66, 2005.

[10] Cowan, D.R., Consolazio, G.R., and Davidson, M.T., "Response-Spectrum Analysis for Barge Impacts on Bridge Structures", ASCE Journal of Bridge Engineering, 20(12):04015017, 2015. 
[11] Getter, D.J., Consolazio, G.R., and Davidson, M.T., "Equivalent Static Analysis Method for Barge Impact-Resistant Bridge Design”, ASCE Journal of Bridge Engineering, 16(6):71827, 2011.

[12] Patev, R.C., Barker, B.C., and Koestler III, L.V., Prototype Barge Impact Experiments, Allegheny Lock and Dam 2, Pittsburgh, Pennsylvania, U.S. Army Corps of Engineers (USACE) Report, Washington D.C., 2003.

[13] Ebeling, R.M., White, B.C., Mohamed, A.N., and Barker, B.C. Force Time History During the Impact of a Barge Train with a Lock Approach Wall Using Impact_Force. U.S. Army Corps of Engineers Research and Development Center, ERDC/ITL TR-10-1, 2010.

[14] Ebeling, R. M., and Warren, T. W., Limiting Impact Force Due to Yielding and Buckling of the Plates and Internal Structural Frame at the Impact Corner of the Barge during Its Glancing Blow Impact with a Lock Approach Wall, U.S. Army Corps of Engineers Research and Development Center, ERDC/ITL TR-08-2, 2008.

[15] LSTC, LS-DYNA Theory Manual, Livermore Software Technology Corporation, Livermore, CA, 2014.

[16] Consolazio, G.R., Walters, R.A., Harper, Z.S., Development of Finite Element Models for Studying Multi-barge Flotilla Impacts. Structures Research Report No. 2010/87754, University of Florida, Gainesville, Florida, 2012. 
[17] Consolazio, G.R., Davidson, M.T., and Getter, D.J., Development and Support of Dynamic Numerical Modeling of Aberrant Rake Barges Impacting Hurricane Protection Structures Subjected to Forces from a Hurricane Environment, Final report to U.S. Army Corps of Engineers, Structures Research Report 2010/83710, University of Florida, Department of Civil and Coastal Engineering, 112 p., 2010.

[18] Jones, N. Structural Impact, Cambridge University Press, New York, NY, 1997.

[19] Gaythwaite, J.W., Design of Marine Facilities for the Berthing, Mooring, and Repair of Vessels, 2nd Edition, American Society of Civil Engineers, Reston, VA, 2004.

[20] American Society for Testing and Materials, "Standard Specification for Stranded Carbon Steel Wire Ropes for General Purposes", American Society for Testing and Materials, ASTM A1023-09, West Conshohocken, PA, 2009.

[21] Ebeling, R.M., Mohamed, A.N., Arroyo, J.R., White, B.C., Strom, R.W., and Barker, B.C., Dynamic Structural Flexible-Beam Response to a Moving Barge Train Impact Force Time-History Using Impact_Beam, U.S. Army Corps of Engineers Research and Development Center, ERDC/ITL TR-11-1, 2011.

[22] Consolazio, G.R., Walters, R.A., Development Of Multi-Barge Flotilla Finite Element Models For Use In Probabilistic Barge Impact Analysis Of Flexible Walls, Final report to U.S. Army Corps of Engineers, Structures Research Report 2012/94753, University of Florida, Department of Civil and Coastal Engineering, 79 p. 2012. 
[23] Consolazio, G.R., Fung, J., Ansley, M., “M- $\Phi-P$ Diagrams for Concrete Sections Under Biaxial Flexure and Axial Compression", American Concrete Institute (ACI) Structural Journal, Vol. 101, No. 1, 2004, pp. 114-123. 